\title{
Asymmetric hydrosilylation, transfer hydrogenation and hydrogenation of ketones catalyzed by iridium complexes
}

\author{
Raluca Malacea, $₫$ Rinaldo Poli and Eric Manoury \\ CNRS; LCC (Laboratoire de Chimie de Coordination); 205, route de Narbonne ; Université \\ de Toulouse; UPS, INP; F-31077 Toulouse, France; Fax: (+) 33-561553003
}

Dedicated to Prof. Fausto Calderazzo on the occasion of his 80th birthday.

\begin{abstract}
Iridium-based asymmetric reduction of ketones to chiral enantiomerically enriched alcohols has recently attracted attention by a number of research groups and interest in this area is growing. This review presents the different catalytic systems based on iridium complexes that have been used in asymmetric hydrosilylation, in asymmetric transfer hydrogenation (ATH) with alcohols or formic acid derivatives as reducing agents, and in asymmetric hydrogenation $\left(\mathrm{H}_{2}\right.$ as reducing agent). A large variety of chiral ligands of various denticities and bearing various combination of coordinating atoms $(\mathrm{N}, \mathrm{P}, \mathrm{S}, \mathrm{O}, \mathrm{C}, \ldots)$ have been used and will be presented. The last part critically reviews the mechanistic understanding of all the above transformations with specific reference to iridium catalysts.
\end{abstract}

\section{Keywords}

Iridium; chiral alcohols; asymmetric hydrosilylation; asymmetric transfer hydrogenation; asymmetric hydrogenation; mechanisms; iridium hydrides.

\footnotetext{
* Present address: Université de Bourgogne ; ICMUB UMR CNRS 5260 ; 9 av. A. Savary, BP 47870 ; 21078 Dijon Cedex France.
} 
Outline

1. Introduction 2

2. Asymmetric hydrosilylation of ketones with iridium 4

2.1. $\mathbf{P}, \mathbf{N}$ ligands 4

2.2. Other ligands 6

3. Asymmetric transfer hydrogenation (ATH) of ketones with iridium 8

3.1. $P$ and $P, P$ ligands $\quad 8$

3.2. $\mathbf{N}, \mathbf{N}$ ligands $\quad 10$

3.3. N,O ligands 20

3.4. N,S ligands 20

3.5. Other bidentate ligands 23

3.6. Tri and tetradentate ligands 23

4. Asymmetric hydrogenation (AH) of ketones with iridium 27

$\begin{array}{ll}\text { 4.1. } P, P \text { ligands } & 27\end{array}$

4.2. $\mathrm{N}, \mathrm{N}$ ligands $\quad 30$

4.3. Other ligands $\quad 34$

5. Mechanistic considerations 36

5.1 Hydrosilylation 36

5.2 Transfer hydrogenation and hydrogenation 37

5.2.1. Survey of the proposed mechanisms

5.2.2. Open questions $\quad 45$

(a) $\operatorname{Ir}(I)$ or $\operatorname{Ir}($ III $) ?$

(b) Denticity/activity relationship $\quad 47$

(c) Solvent effects on activity and on enantioselectivity 48

(d) Is diene removal in "Ir(diene)"-type pre-catalysts necessary? 48

5.2.3. Computational studies $\quad 50$

7. References $\quad 52$

\section{Introduction}

Alcohols are very important building blocks for the pharmaceutical and fine chemical industries. Although many applications require racemic alcohols, the need for enantiomerically pure products is growing because of their significance as intermediates for the manufacture of 
pharmaceuticals and advanced materials [1], raising great interest in finding new methods for their production. In addition, ketones are one of the most common families of unsaturated substrates, therefore the enantioselective reduction of prochiral ketones leading to optically pure secondary alcohols is a subject of considerable interest from both the academic and the industrial perspectives. Enzymes that catalyse ketone reduction (known as ketoreductase) are reliable tools leading to highly enantiomerically enriched chiral alcohols. Over the past years, a library of ketoreductases has been used to reduce ketones across several structural classes [2]. Kinetic resolution of racemic alcohols with chiral catalysts or enzymes, has also attracted industrial interest [3]. However, the most elegant approach is enantioselective catalysis where prochiral starting materials are transformed into enantioenriched products with the help of chiral catalysts. Different perfumery ingredients, for instance alcohols responsible for woody odour, are obtained by hydrogenation of the corresponding carbonyl substrates [4]. The success of hydrogenation relies primarily on the proper combination of a metal and a ligand; therefore considerable efforts have been devoted to the development of transition metal complexes as catalysts. The majority of the work carried out in this area has employed ruthenium-based catalysts in combination with a variety of phosphine and amine ligands [5]. Of these, the most notable is a transfer hydrogenation system which incorporates the $\mathrm{Ru}(\mathrm{II})$-TsDPEN (TsDPEN=N-( $p$-toluenesulfonyl)-1,2-diphenylethylenediamine) catalyst, first reported by Noyori et al. [6]. More recently, the synthesis and application of efficient rhodium-based catalysts has been also reported in the literature [7]. However, the interest in iridium catalysts, which have often been successfully used for the asymmetric hydrogenation of olefins [8], is rapidly growing in recent years. Iridium has the advantage to be much less expensive than rhodium [9]. To the best of our knowledge, no review dedicated to the asymmetric reduction of ketones has so far been published [10]. The catalytic reduction of ketones to the corresponding alcohols can be carried out by hydrosilylation followed by hydrolysis (Eq. 1), by transfer hydrogenation, usually in the presence of an alcohol as a hydrogen donor and a base (Eq. 2), or by hydrogenation where the reducing agent is molecular hydrogen (Eq. 3). A problem of the transfer hydrogenation reaction in 2-propanol is the reversibility of the process. To optimize conversion in 2-propanol, the catalysis must be performed using very low substrate concentrations. On the other hand, the reaction is irreversible with formic acid as hydrogen donor because of $\mathrm{CO}_{2}$ evolution. 
<smiles>[R]C([Y])=O</smiles>

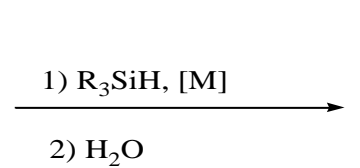<smiles>[R]C([Y])O</smiles>

Equation 1<smiles>[R]C([Y])=O</smiles><smiles>CC(C)(C)CC(C)(C)P</smiles>

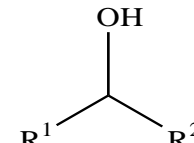

Equation 2 $\mathrm{DH}_{2}: \mathrm{CH}_{3} \mathrm{CHOHCH}_{3}, \mathrm{HCOOH}, \mathrm{HCOONa},$.<smiles>[R]C([R])=O</smiles><smiles>[R]C([R])O</smiles>

Equation 3

The first part of this review will be focussed on the asymmetric hydrosilylation of ketones while the second part will treat the asymmetric transfer hydrogenation (ATH). Then, the third part will deal with the catalytic hydrogenation, which has so far received less attention. In a fourth and final part, we shall critically review the mechanistic understanding of all the above transformations with specific reference to iridium catalysts

\section{Asymmetric hydrosilylation of ketones with iridium}

In recent years, asymmetric hydrosilylation of ketones has been recognised as a valuable way to obtain chiral secondary alcohols because of the often milder conditions needed to carry out the reaction in comparison with hydrogenation reactions. Various metallic complexes based on titanium, zinc, copper, ... and especially on rhodium have been used to catalyze this reaction [11], but iridium complexes have rather seldom been tested.

\section{1. $\mathbf{P}, \mathbf{N}$ ligands}

In 1985, Nile et al. described the first attempt of asymmetric hydrosilylation of ketones catalyzed by iridium complexes in the presence of a P,N ligand with satisfactory yields but low enantiomeric excesses (see scheme 1) [12].

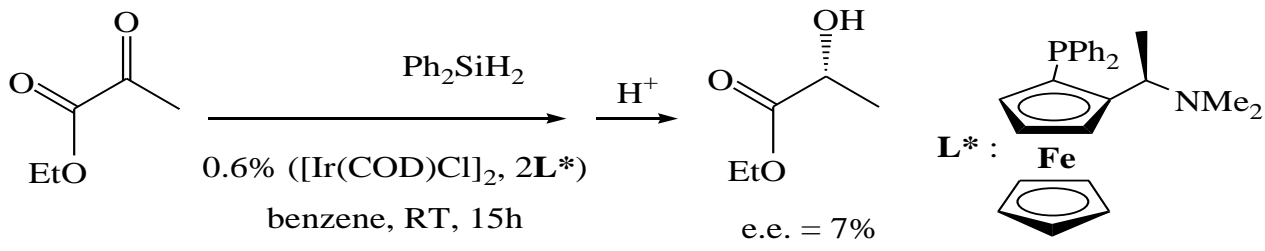

Scheme 1 
Kreuzfeld and coworkers used another P,N ligand, named amphos 1 (Scheme 2), in the hydrosilylation of acetophenone by diphenylsilane [13]. Good conversions could be obtained, but with low e.e., lower than with the corresponding rhodium systems with the same ligand (up to $50 \%$ and with opposite absolute configuration).

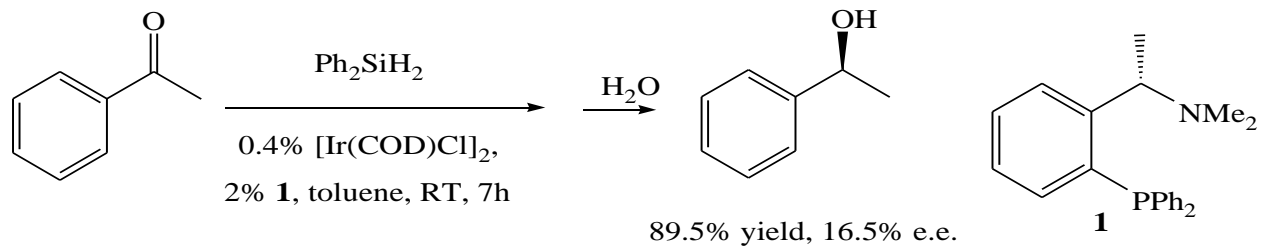

Scheme 2

However, using the oxazolylphosphine ligand DIPOF, Uemura could develop iridiumbased catalytic systems with good activities and high enantioselectivities (scheme 3) [14]. If the product absolute configuration was opposite, as usual, when iridium was used instead of rhodium, the enantioselectivities were significantly higher (for acetophenone: $96 \%$ with iridium, 91\% with rhodium).
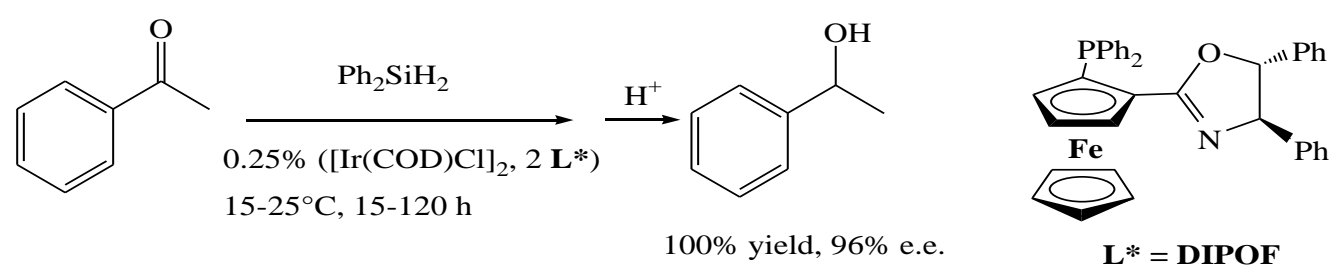

Scheme 3

High yields and enantioselectivities could also be obtained for various aryl-alkyl or heteroaryl-alkyl ketones but not with hindered ketones or dialkyl ketones (see scheme 4). 


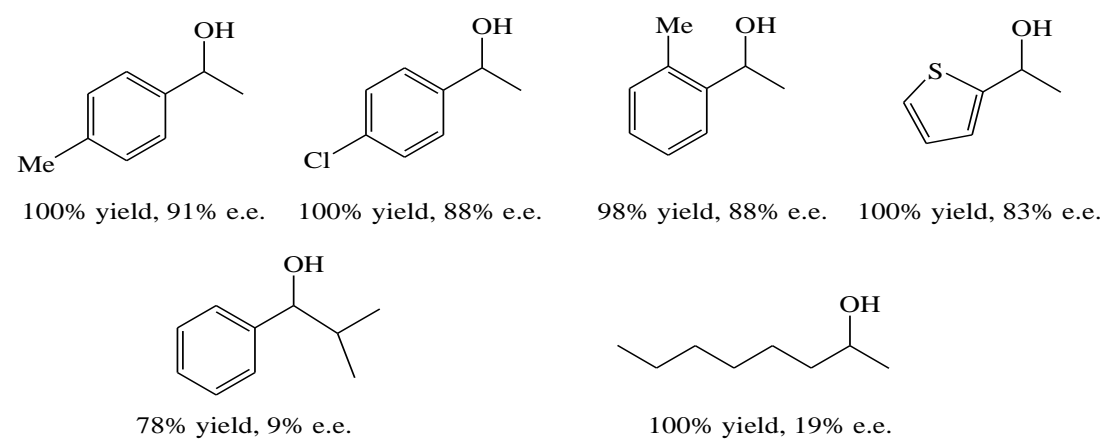

Scheme 4

Moberg et al. used cationic iridium complexes of other phosphine-oxazolines bearing a hydroxyl group in the asymmetric hydrosilylation of various ketones (scheme 5) [15]. Good yields were obtained after $16 \mathrm{~h}$ (quasi-quantitative conversions but with 2-10\% of silyl enol ether) with good enantioselectivities for aromatic ketones. With this ligand, iridium-based systems were again less selective than their rhodium counterparts.

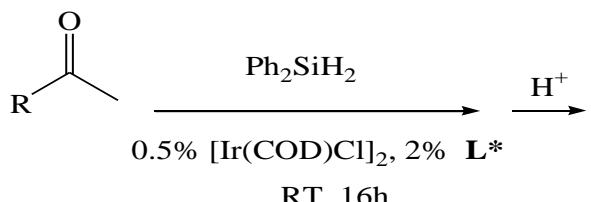

RT, $16 \mathrm{~h}$

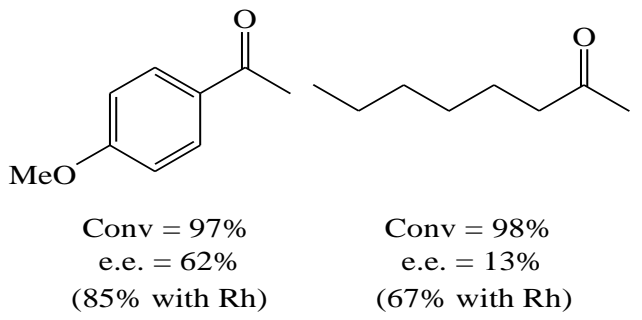

(67\% with $\mathrm{Rh})$<smiles>OC(c1ccccc1)[C@H]1COC(c2ccccc2P)=N1</smiles><smiles>CC(=O)CCc1ccccc1</smiles>

Scheme 5

\subsection{Other ligands}

The use of tridentate $\mathrm{P}, \mathrm{N}, \mathrm{S}$ chiral ligands with $[\mathrm{Ir}(\mathrm{COD}) \mathrm{Cl}]_{2}$ as precatalyst by Faller et al. gave up to $33 \%$ e.e. in the hydrosilylation of acetophenone by diphenylsilane (see scheme 6) [16]. However, the reactions were slower, less enantioselective (e.e. up to $64 \%$ with the best ligand 2) and, once again, with opposite absolute configuration than with the corresponding rhodium systems. 


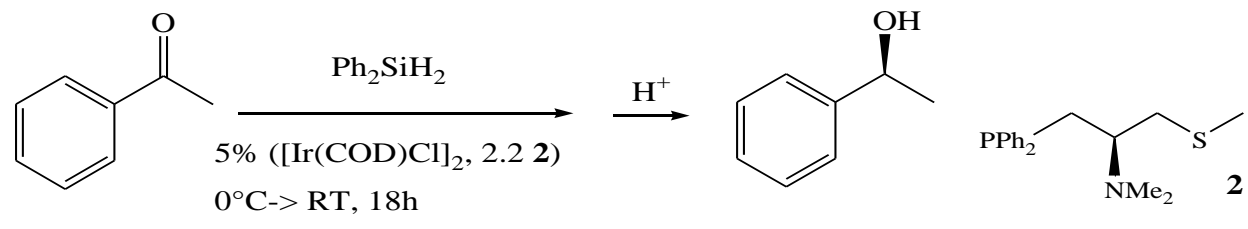
$92 \%$ yield, $33 \%$ e.e.

Scheme 6

Lower e.e. were also reported by Uemura et al. with the diferrocenyl dichalcogenide ligands 3 (e.g. for ligand $\mathbf{3 b}$ : e.e. up to $23 \%$ for Ir, $85 \%$ for Rh, see scheme 7) [17].
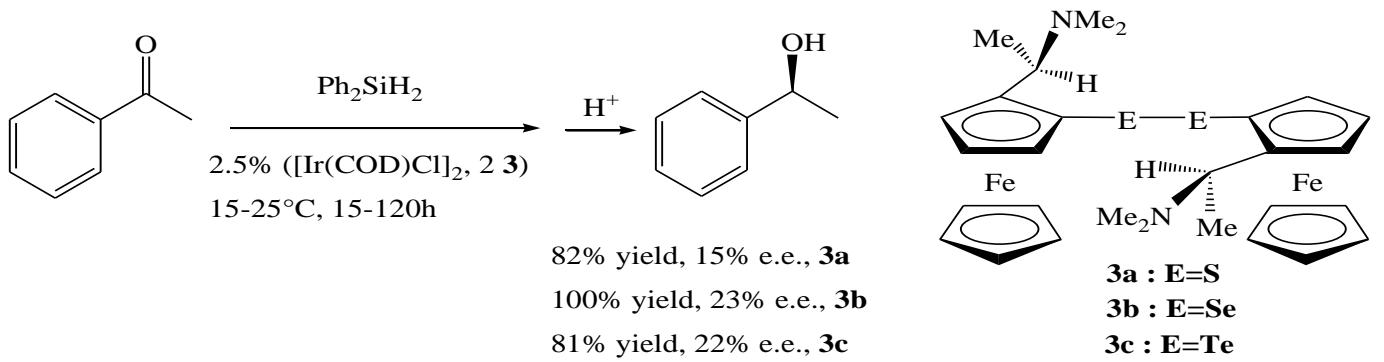

\section{Scheme 7}

Iridium and rhodium complexes of carbene-naphtoxy ligands have been used by Crabtree et al. in the asymmetric hydrosilylation of acetophenone by diphenylsilane (Scheme 8) [18]. Rhodium complexes gave high activities but low enantioselectivities (e.e. up to 23\%), whereas the corresponding iridium complexes gave slightly lower activities, lower chemoselectivities (ca. $15 \%$ of silyl enol ether produced, see scheme 8), but better enantioselectivities (e.e. up to $60 \%)$.

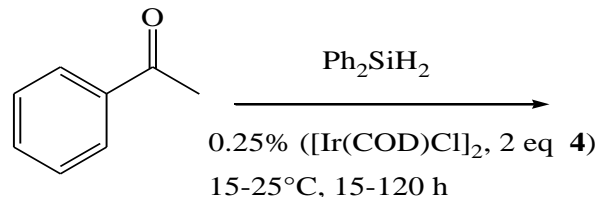<smiles>CC(O[SnH2]c1ccccc1)c1ccccc1</smiles>

$$
\begin{aligned}
& 97 \% \\
& 97 \% \\
& 85 \%
\end{aligned}
$$$$
83 \%
$$<smiles>C=C(O[GaH2])c1ccccc1</smiles>

$3 \%$ with4a $3 \%$ with $\mathbf{4 b}$ $15 \%$ with $\mathbf{4 c}$ $17 \%$ with $4 d$

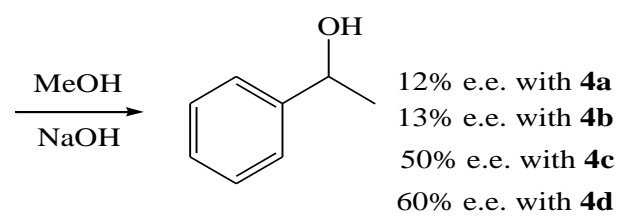

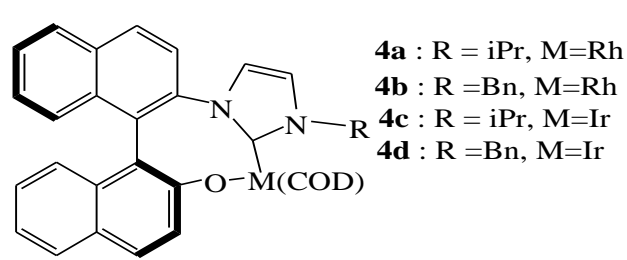

Scheme 8 
In conclusion, if some interesting asymmetric hydrosilylation systems based on iridium have been developed, they are still much rarer than systems based on other metals (in particular, rhodium, titanium, copper) and they do not seem competitive in terms of catalytic activities and enantioselectivities [4].

\section{Asymmetric transfer hydrogenation (ATH) of ketones with iridium}

Since the pioneering work of Mestroni et al. on the use of iridium complexes in the transfer hydrogenation of ketones [19], numerous iridium-based catalytic systems have been studied. Most of these systems are asymmetric ones. Various types of chiral ligands have been studied. The different catalytic systems will be presented according to the coordination pattern of the ligands involved.

\section{1. $P$ and $P, P$ ligands}

One of the first reports on the iridium-based ATH of ketones was by Graziani in 1982 [20]. Dichlorobis (1,4-cyclooctadiene)diiridium $\left([\operatorname{Ir}(\mathrm{COD}) \mathrm{Cl}]_{2}\right)$ was used as a precatalyst in the presence of chiral phosphines (Scheme 9) for the asymmetric reduction of various ketones with isopropanol as a hydrogen source. The work was extended in 1986, in particular by studying the precatalyst activation conditions [21]. A first activation time (T1) of $[\operatorname{Ir}(\mathrm{COD}) \mathrm{L}]^{+}$in refluxing isopropanol, followed by a second activation time (T2) under the same conditions but in presence of 8 equivalents of $\mathrm{KOH}$, were necessary for optimum catalytic performance. The precise structures of the different species produced during the activation process were not determined by the authors, but the presence of different iridium hydrides at the end of the first activation time (T1) was revealed by ${ }^{1} \mathrm{H}$ NMR. Although the influence of T1 and T2 on the catalytic activities was low, the enantioselectivities dramatically changed. Thus, using the same precatalyst $[\operatorname{Ir}(\mathrm{COD}) \mathrm{CHIRAPHOS}]^{+}$, the reduction of acetophenone yields the corresponding alcohol with an e.e. of $28 \%$ in favour of the $\mathrm{S}$ enantiomer if $\mathrm{T} 1=15 \mathrm{~min}$ and $\mathrm{T} 2=15 \mathrm{~min}$ but an e.e. of $11 \%$ in favour of the $\mathrm{R}$ enantiomer if $\mathrm{T} 1=7 \mathrm{~h}$ and $\mathrm{T} 2=15 \mathrm{~h}$. High levels of enantioselectivities were observed with the PROPHOS ligand (up to $66 \%$ in the hydrogenation of PhCOEt). 


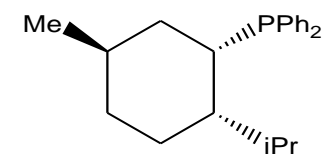

NMDPP

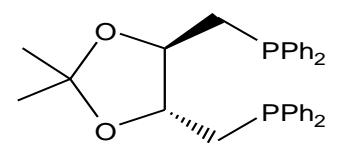

DIOP

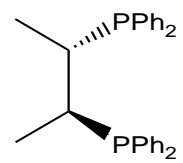

CHIRAPHOS

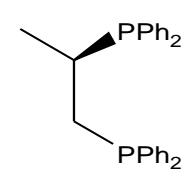

PROPHOS

Scheme 9.

Similar iridium complexes obtained by the in situ reaction of $[\operatorname{Ir}(\mathrm{COD})(\mathrm{acac})]$, one equivalent of $\mathrm{HBF}_{4}$ and two equivalents of monophosphine menthyldiphenylphosphine (MDPP) or dimenthylphenylphosphine (DMPP) (scheme 10), also proved active as catalysts for the ATH of some aryl alkyl ketones [22].

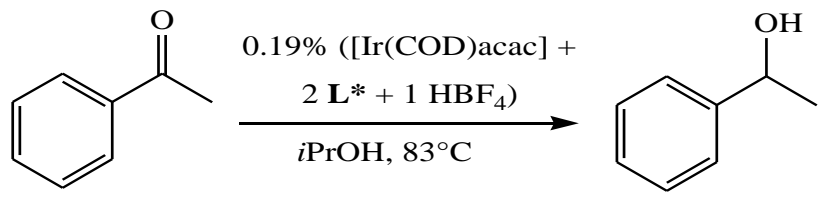

$54.4 \%$ yield after $8 \mathrm{~h}, 39.4 \%$ e.e. with MDPP (up to $47.8 \%$ e.e. at RT with $\mathrm{L}^{*} /[\mathrm{Ir}]=10$ )

$81.6 \%$ yield after $8 \mathrm{~h}, 39.5 \%$ e.e. with DMPP<smiles>C[C@@H]1CC[C@@H](P)[C@H](P)C1</smiles>

MDPP

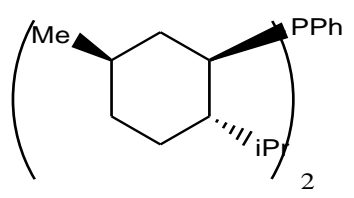

DMPP

Scheme 10.

Contemporarily, Bakos et al. found that in situ prepared iridium (and rhodium) complexes of phosphinites (BDPOP, BDPODP, see scheme 11) could also catalyze the ATH of acetophenone within $1 \mathrm{~h}$ in refluxing isopropanol in the presence of strong bases $(\mathrm{NaOMe}$ or $\mathrm{KOH}$ ). Good conversions but moderate enantioselectivities (e.e. up to $18 \%$ with $\mathrm{BDPOP} /[\mathrm{Ir}(\mathrm{COD}) \mathrm{Cl}]_{2}$ at $90^{\circ} \mathrm{C}$ in the presence of $\mathrm{MeONa}$ ) could be achieved [23]. In this catalytic system, Ir complexes gave higher enantiomeric excesses than $\mathrm{Rh}$ complexes. The precatalyst nature $\left([\operatorname{Ir}(\mathrm{COD}) \mathrm{Cl}]_{2}\right.$ or $\left.\left[\operatorname{Ir}(\mathrm{COE})_{2} \mathrm{Cl}\right]_{2}\right)$ had a significant influence on the enantioselectivity, namely higher e.e. were observed with the more strongly coordinated COD (for instance $18 \%$ e.e. vs. only $7 \%$ under the same conditions for the COE system). When the activation step was carried out without base, the enantioselectivies dropped slightly (10\% instead of $18 \%$ with BDPOP). The presence of base in the activation step was shown to retard 
the COD substitution, leading to the hypothesis that this can open new reaction paths leading to higher enantioselectivities.
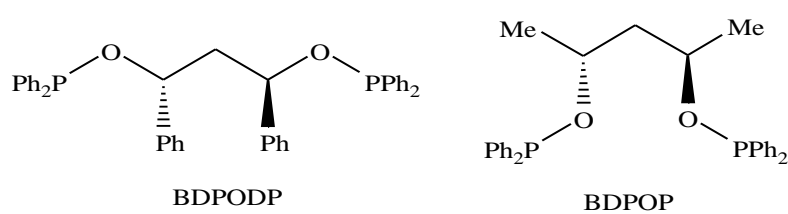

Scheme 11

\section{2. $\mathrm{N}, \mathrm{N}$ ligands}

2-[(N-Alky1imino)methyl pyridines and alkyl(2-pyridylmethy1)amines have often been employed among $\mathrm{N}$-donor ligands as chiral modifiers in the $\operatorname{Ir}(\mathrm{I})$ catalyzed ATH of ketones [24]. For instance, a few preformed tetra- and pentacoordinated $\operatorname{Ir}(\mathrm{I})$ complexes $(\mathbf{5}, \mathbf{6}, \mathbf{7}$, Scheme 12) with bidentate 2 -[(N-alkylimino) methyl pyridines and alkyl(2-pyridylmethy 1$)$ amines have been prepared and tested in the ATH of ketones with propan-2-ol as H donor [25,26]. Most of these were good catalysts affording, in the presence of $\mathrm{KOH}$, greater than $90 \%$ conversion in a few hours at a substrate to iridium ratio of 1000 . Activity and enantioselectivity were strongly dependent on the structure of the chiral ligand and enantiomeric excesses ranging from $1.5 \%$ to 95\% were recorded. In the acetophenone reduction catalyzed by complexes $\mathbf{5}$, the introduction of a phenyl group in place of an alkyl at the stereogenic carbon improves both the activity and the stereoselectivity. For the reaction catalyzed by $\mathbf{5}$, the configuration of the resulting alcohol depends of the substituents $R^{1}-R^{3}$ and was reversed when complex $\mathbf{5} b\left(R^{1}=H ; R^{2}=B z ; R^{3}=\right.$ $\mathrm{Ph} ; \mathrm{R}=\mathrm{H})$ was used $(41.5 \% \mathrm{~S})$ instead of $\mathbf{5 a}\left(\mathrm{R}^{1}=\mathrm{H} ; \mathrm{R}^{2}=\mathrm{Me} ; \mathrm{R}^{3}=\mathrm{Ph} ; \mathrm{R}=\mathrm{H}\right)(15 \% \mathrm{R})$. When the catalyst was prepared "in situ" from $\left[\operatorname{Ir}(\mathrm{COE})_{2} \mathrm{Cl}\right]_{2}$ and the corresponding ligand, lower e.e. were obtained.
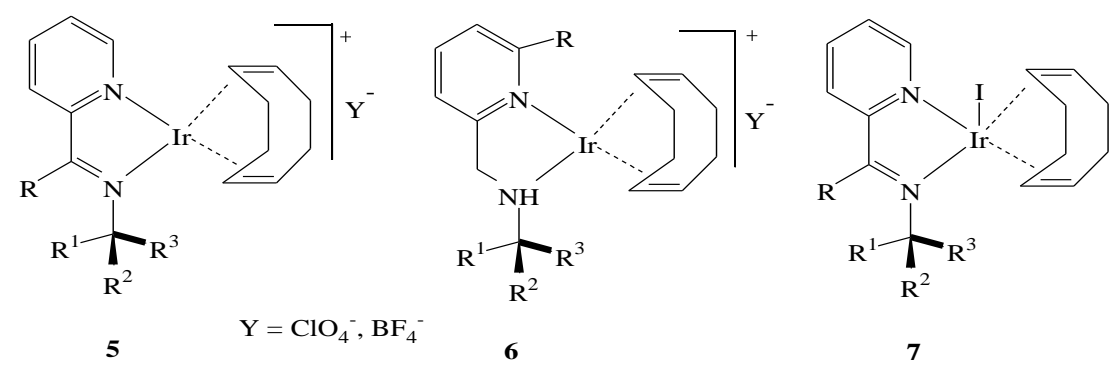

7

Scheme 12 
A significant improvement of the stereoselectivity of the ATH was obtained upon introduction of pentacoordinated neutral iridium complexes 7 as preformed catalysts. For instance, complex 7a $\left(\mathrm{R}^{1}=\mathrm{H} ; \mathrm{R}^{2}=\mathrm{Me} ; \mathrm{R}^{3}=\mathrm{Ph} ; \mathrm{R}=\mathrm{H}\right)$ promotes the ATH of tert-butyl phenyl ketone with $79.5 \%$ e.e. instead of $50 \%$ with corresponding 5a. An even better value (84 \%) could be obtained when the reduction was carried out in the presence of additional NaI. This result is one of the best ever reported for the ATH of this sterically hindered ketone, which is usually reduced with difficulty by the other previously considered catalysts.

The use of complexes 5 has also been reported in a patent [27]. When the ATH of $n$-propyl phenyl ketone was carried out in $i-\mathrm{PrOH} / \mathrm{NaOH}$ at $60^{\circ} \mathrm{C}$ and at a [substrate]/[Ir] ratio $=1000$, optical yields in the range 12.5-64.8\% were obtained. Activities and enantioselectivities were found to be highly dependent of the substituents $R, R^{1}-R^{3}$. A significant improvement of the optical yield, from $19 \%$ to $54.2 \%$ and a 10 -fold increase of the reaction rate were obtained when a methyl group was introduced into the 6-position of the pyridine ring. Further increments could be observed by changing the substituents at the stereogenic carbon $\left(65 \%\right.$ e.e. for $R^{1}=H ; R^{2}=$ 1-naphtyl; $\mathrm{R}^{3}=\mathrm{Me} ; \mathrm{R}=\mathrm{M}$ ). In particular, good enantioselectivities were obtained with ligand DHPPEI $\left(\mathrm{R}_{1}=\mathrm{H}, \mathrm{R}_{2}=\mathrm{Me}, \mathrm{R}_{3}=\mathrm{Ph}, \mathrm{R}=\mathrm{H}\right)$ with e.e. up to $90 \%$ in the $\mathrm{ATH}$ of $\mathrm{PhCO}\left(\mathrm{CH}_{2}\right)_{3} \mathrm{Ph}$.

Two styryl derivatives 8 and $\mathbf{9}$ have also been synthesized and used either as homogeneous catalysts or, after immobilization through copolymerization with 2-ethylhexyl methacrylate in presence of divinylbenzene as cross-linking agent, as heterogenized catalysts 10 and 11 (Scheme 13) [24]. Stereoselectivities could be greatly improved going from the homogeneous to the heterogenized systems: the enantiomeric excesses increased from 47 to $85 \%$ and from 52 to $84 \%$ with the methyl and with the benzyl substituted ligands, respectively. In both cases the optical purity of the product did not change as the reaction proceeded. By modification of the polymeric support, the enantioselectivities could be further improved: an enantiomeric excess of $95 \%$ could be obtained at $20 \%$ conversion with a polymeric complex synthesized from tert-butyl methacrylate. 


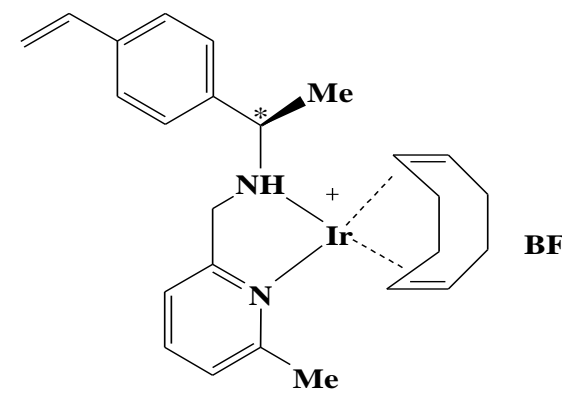

8

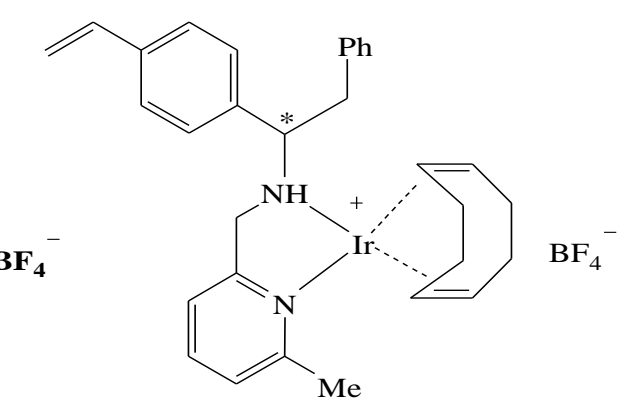

9

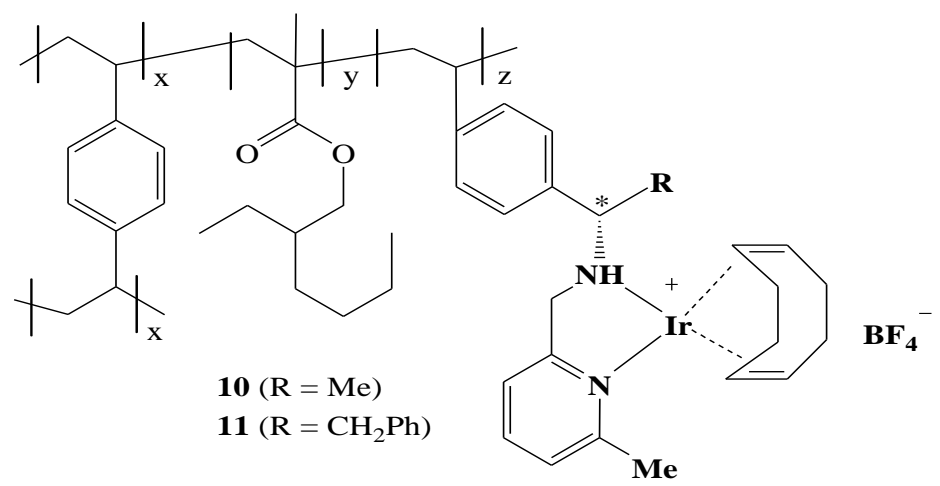

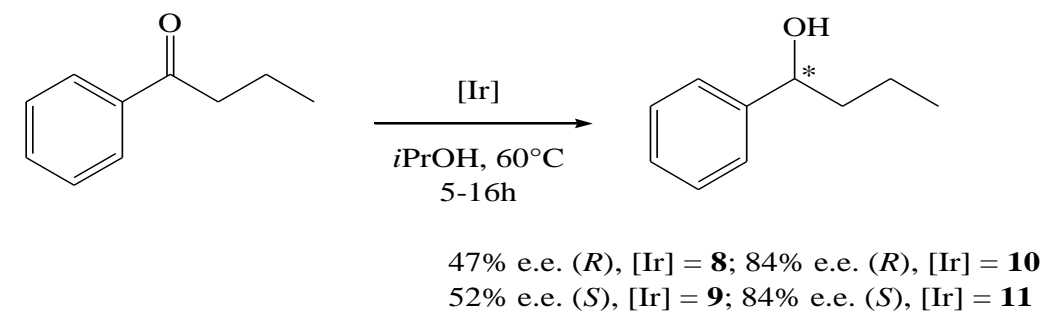

Scheme 13

Preformed $\operatorname{Ir}^{\mathrm{I}}$ complexes with 2-[(N-alkylimino)-methyl]pyridines 12 and alkyl(2pyridylmethyl]amines 13 (Scheme 14) have been used in the ATH of $n$-butyrophenone in isopropanol at $60^{\circ} \mathrm{C}$ with $\mathrm{NaOH}$ as cocatalyst [24]. Tetracoordinated cationic complexes 13 and pentacoordinated neutral species 12 displayed similar efficiencies (64 and 66\% e.e. for 12a and 13a respectively, see scheme 14). Activity and stereoselectivity sharply decreased when a methyl group was introduced on the imino function for ligands $\mathbf{1 2}$ or in the pyridine ring 6position for complexes 13. The heterogenized catalyst, obtained from the styryl monomeric ligand 13c by copolymerization with with 2-ethylhexyl methacrylate in presence of di-2butylbenzene, was more active and enantioselective than the monomeric catalyst (77 vs 68\% e.e. for $\mathbf{1 3 c})$. 


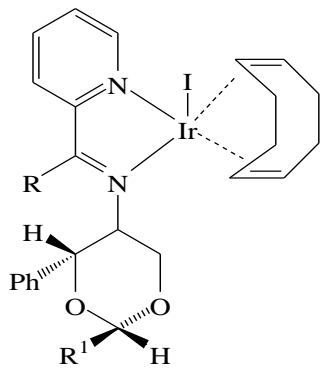

$$
\text { 12a, } \mathrm{R}=\mathrm{H}, \quad \mathrm{R}^{1}=\mathrm{Ph}
$$

12b, $R=M e, R^{1}=P h$

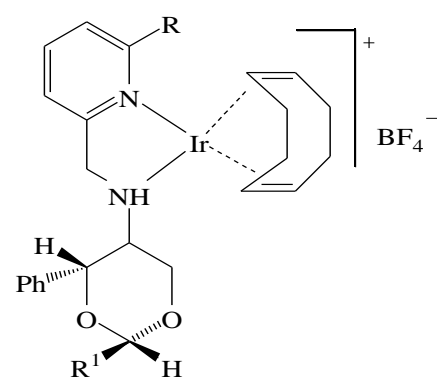

13a, $\mathrm{R}=\mathrm{H}, \quad \mathrm{R}^{1}=\mathrm{Ph}$

13b, $\mathrm{R}=\mathrm{Me}, \mathrm{R}^{1}=\mathrm{Ph}$

13c, $R=H, \quad R^{1}=4$-styryl

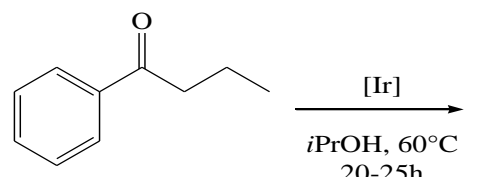

$20-25 h$

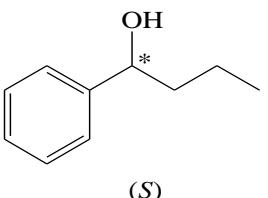

(S)

$64 \%$ e.e., $[\mathrm{Ir}]=\mathbf{1 1 a}$

$3 \%$ e.e., $[\mathrm{Ir}]=\mathbf{1 1 b}$

$66 \%$ e.e., $[\mathrm{Ir}]=\mathbf{1 2 a}$

$24 \%$ e.e., $[\mathrm{Ir}]=\mathbf{1 2 b}$

$68 \%$ e.e., $[\mathrm{Ir}]=\mathbf{1 2 c}$

\section{Scheme 14}

Pfaltz and co-workers [28] showed that $\operatorname{Ir}^{\mathrm{I}}$ catalysts prepared "in situ" from $[\mathrm{Ir}(\mathrm{COD}) \mathrm{Cl}]_{2}$ and enantiomerically pure $\mathrm{C} 2$-symmetric bisoxazolines 14a (scheme 15) display good activity in the ATH of ketones in refluxing $i \mathrm{PrOH}$ in the presence of $\mathrm{KOH}$. Alkyl aryl ketones were readily reduced, affording the corresponding alcohols in $47-91 \%$ e.e., whereas dialkyl ketones were less reactive and gave low yields of racemic products. The best result was obtained with the isopropyl substituted ligand and isopropyl phenyl ketone as the substrate (91\% e.e. at $70 \%$ conversion). The size of the bisoxazoline ligands chelate ring appears to be critical since Ir $^{\mathrm{I}}$ complexes with six-membered rings derived from ligands $\mathbf{1 4 b}$ did not show any significant catalytic activity.

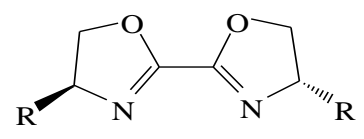

$14 a$

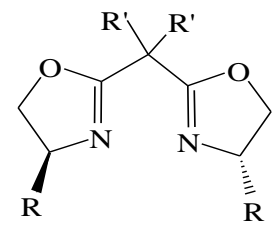

14b

Scheme 15 
The chiral bis(oxazoline)-Ir(I) complex 15 was prepared and used for the ATH of acetophenone in $i \mathrm{PrOH}$ in presence of $t \mathrm{BuOK}$ as base, but with only modest results (Scheme 16) [29].
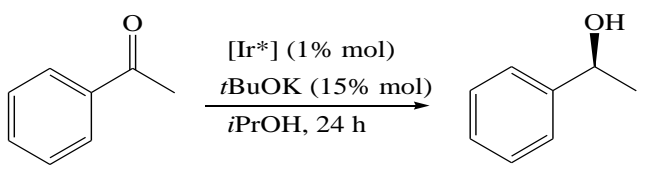

yield $=22 \%$ e.e. $=20 \%$

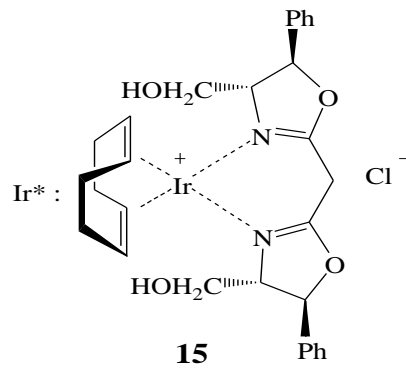

\section{Scheme 16}

Lemaire et al. used ureas $\mathbf{1 6}$ (see scheme 17) as chiral ligands in the ATH of propiophenone in the presence of $[\operatorname{Ir}(\mathrm{COD}) \mathrm{Cl}]_{2}$ and $t \mathrm{BuOK}$ in isopropanol at $60^{\circ} \mathrm{C}$ [30]. After 9 days, the conversion was almost complete but the enantioselectivity was moderate (e.e. $=57 \%$ ). For this ligand, the iridium-based catalytic system was less active and enantioselective than its rhodiumbased counterpart.

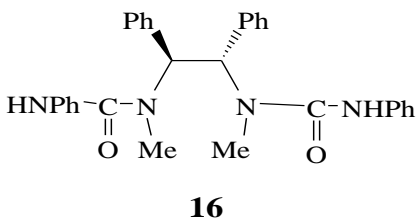

\section{Scheme 17}

Uemura tested ligands 3 also in the ATH of acetophenone in the presence of $[\operatorname{Ir}(\mathrm{COD}) \mathrm{Cl}]_{2}$ and $\mathrm{NaOH}$ in refluxing isopropanol to give the $(R)$-phenylethanol with moderate yields and enantioselectivities (Scheme 18) [31].

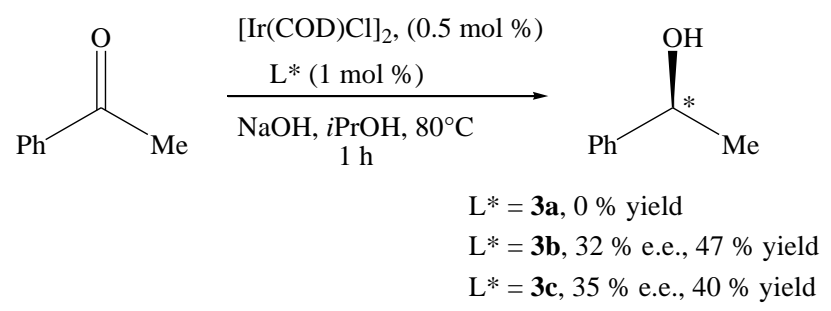

\section{Scheme 18}


Another catalytic system with chiral amine ligands for ATH was reported by Inoue and Noyori [32]. The iridium(I) complexes were prepared from $[\operatorname{Ir}(\mathrm{COD}) \mathrm{Cl}]_{2}$ and 1,1-di(panisyl)ethylene-diamine derivatives 17 (scheme 19). The ATH of alkyl aryl ketones was carried out in 2-propanol at room temperature in the presence of potassium hydroxide. For acetophenone, the reduction product was obtained after $12 \mathrm{~h}$ in good yields (68-96\%) and good enantioselectivities. Many other aryl alkyl ketones were also tested but only with the $[\operatorname{Ir}(\mathrm{COD}) \mathrm{Cl}]_{2} / \mathbf{1 7} \mathbf{c}$ system, yielding, in most cases, the corresponding alcohols in good yields and with good e.e. (see scheme 19).

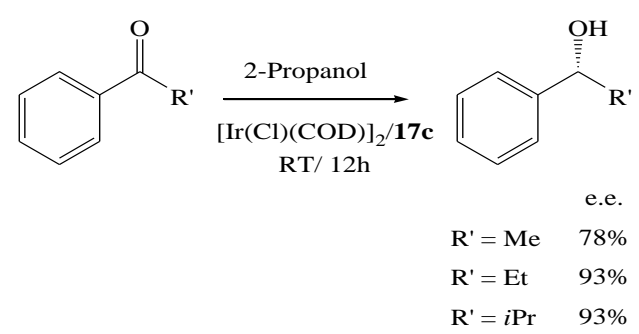

Scheme 19

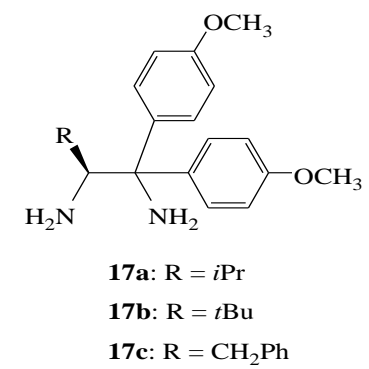

17c: $\mathrm{R}=\mathrm{CH}_{2} \mathrm{Ph}$

Some chiral nitrogen ligands 18-20 (see Scheme 20) obtained from $t$-stilbenediamine have been tested by Lemaire et al. in the ATH of acetophenone in $i \mathrm{PrOH} / t \mathrm{BuOK}$ [33]. Although very low enantioselectivities were obtained using ligands 18 and 19, ligand 20 yielded up to 92\% e.e.
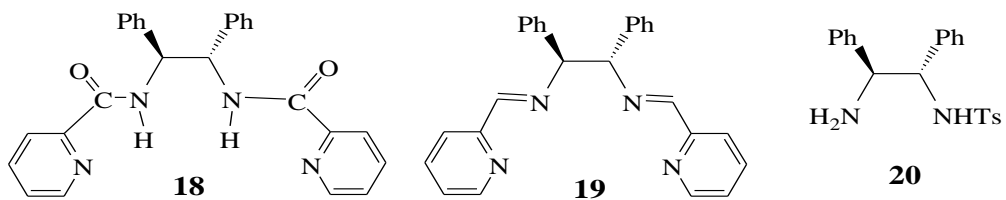

Scheme 20

The Schiff bases derived from diaminocyclohexane (21, 22, scheme 21) were used in the presence of $[\operatorname{Ir}(\mathrm{COD}) \mathrm{Cl}]_{2}$ for the ATH of different aryl alky ketones in $i \mathrm{PrOH} / \mathrm{KOH}$ [34]. Only moderate enantioselectivities were obtained (maximum: 61\% with 21 and 50\% with 22, in both cases for the hydrogenation of 2-fluorenyl methyl ketone). 


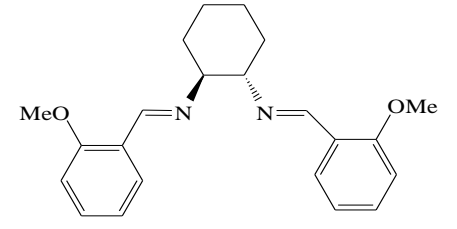

21

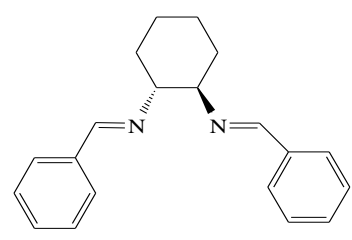

22

Scheme 21

A collection of chiral diamine ligands (23-28, Scheme 22), derived from the Cinchona alkaloids quinine and quinidine, was evaluated in the catalytic ATH of aromatic ketones. Active catalysts were obtained from $[\operatorname{Ir}(\mathrm{COD}) \mathrm{Cl}]_{2}$, capable of reducing a range of aromatic ketones with excellent conversions and good enantioselectivities. The latter were in the $74-85 \%$ range for acetophenone and between 65-94\% for other alkyl aryl ketones, the highest one being obtained with ligand $\mathbf{2 4}$ in the hydrogenation of phenyl isopropyl ketone [35].

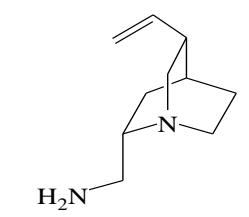

23

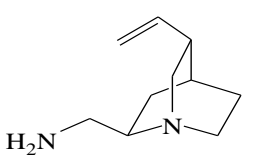

24

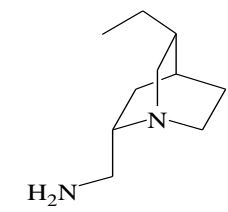

25

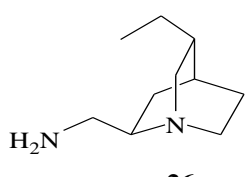

26
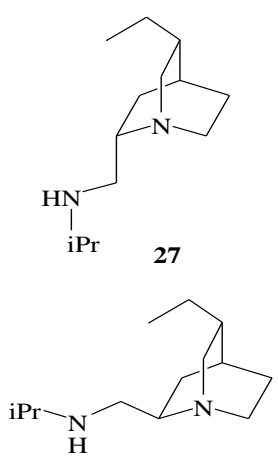

28

Scheme 22

The preformed or in situ prepared iridium complexes of the new chiral diamine $\mathbf{2 9}$ have been tested in the $\mathrm{ATH}$ of ketones in isopropanol in presence of $\mathrm{KOtBu}[36]$. At $55^{\circ} \mathrm{C}$, excellent conversions (up to $100 \%$ ) but moderate enantioselectivities could be achieved (see scheme 23).
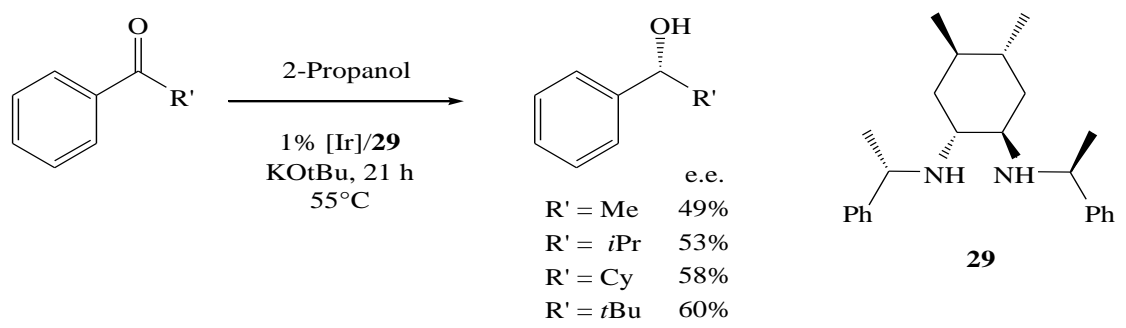

29

Scheme 23 
Andersson et al. synthesized a family of 2-azanorbornane-oxazolines $\mathbf{3 0}$ (see scheme 24) and tested them in the ATH of acetophenone [37]. In comparison with Ru or Rh-based systems, iridium catalysts were less active but more enantioselective. Both activities and enantioselectivities were highly dependent on the oxazoline ring $\mathrm{R}$ substituent but also on the relative configuration of the two asymmetric carbon atoms as illustrated for the two diastereoisomeric ligands 30a and 30b. In addition, it was found that the e.e. increased with conversion.
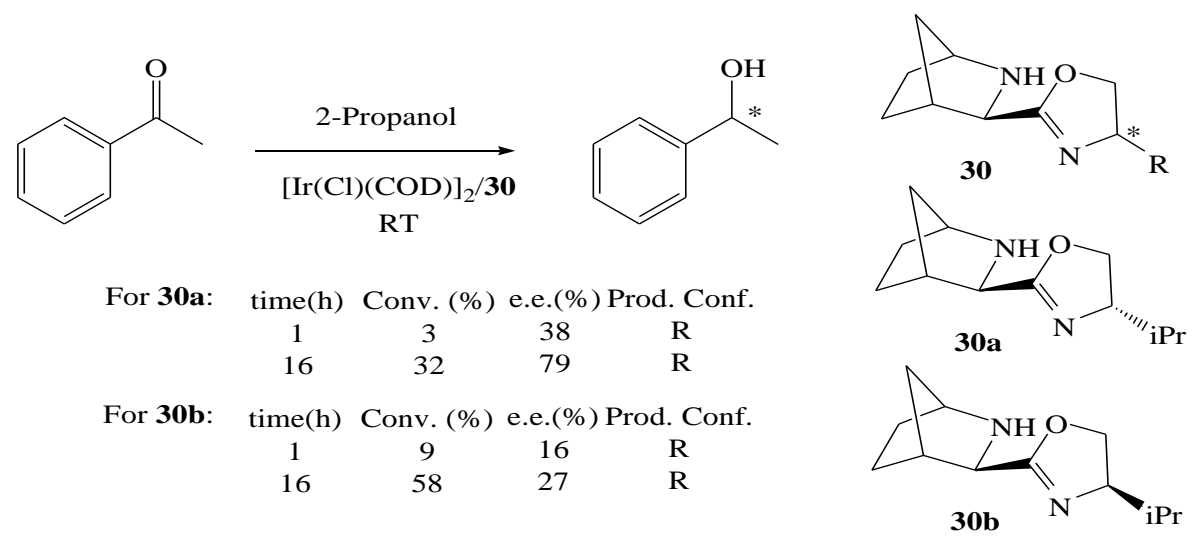

Scheme 24.

The use of monotosylated diamines and 1,2-aminoalcohols as ligands was first reported by Noyori and co-workers for the ruthenium catalyzed ATH of aromatic ketones [38]. The Cp* iridium complex of (1S,2S)-N-(p-toluenesulfonyl)-1,2-diphenylethylenediamine 31 (scheme 25) has been shown to be active for the ATH of acetophenone, 2-acetonaphthone, 1-tetralone, and 1-indanone to give (S)-1-phenylethanol (90\% e.e.), (S)-1-(2-naphthyl)ethanol (81\% e.e.), $(S)$-1-tetralol (96\% e.e.), and $(S)$-indanol (91\% e.e.) [39]. The reaction was carried out in $i \mathrm{PrOH} / \mathrm{KOH}$ at room temperature. The $\mathrm{KOH} / 31$ molar ratio plays an important role, the best yield being obtained for a 1:1 ratio. The similar complex 32 (scheme 25) was used by Ikariya and Noyori [40] for the ATH of acetophenone in $i \operatorname{PrOH} / t \mathrm{BuOK}$, a $96 \%$ enantioselectivity being obtained but with a poor conversion ( $36 \%$ after $12 \mathrm{~h}$ ). For $m \mathrm{CF}_{3} \mathrm{C}_{6} \mathrm{H}_{4} \mathrm{COCH}_{3}$ under the same conditions, the reaction was complete after $24 \mathrm{~h}$ and the corresponding alcohol was obtained with a $94 \%$ e.e. 


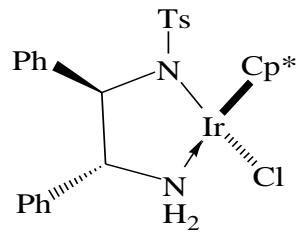

31

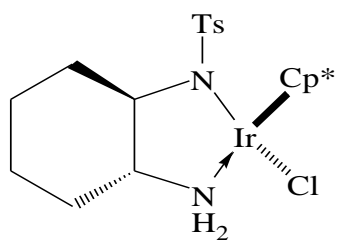

32

Scheme 25

Williams reported the synthesis and application of efficient water-soluble analogues of complexes 31 and 32 for ATH in aqueous media [41]. The chiral iridium complexes were prepared by reacting $\left[\mathrm{Cp}^{*} \mathrm{IrCl}_{2}\right]_{2}$ with the diamine ligands $\mathbf{3 3}$ or $\mathbf{3 4}$ (scheme 26) in the presence of a base $\left(\left[\mathrm{Cp}^{*} \mathrm{MCl}_{2}\right]_{2} /\right.$ ligand/base $\left.=1: 8: 8\right)$. Various aryl alkyl ketones were tested as substrates for ATH in 2-propanol/water (15\%) at RT. In general, good stereoselectivies were observed, ligand $\mathbf{3 3}$ providing in all cases lower enantioselectivities (in the $73-91 \%$ range) than ligand 34 (93-97\% under the same conditions). The same effect was observed in terms of activity (for instance, $98 \%$ conversion with $\mathbf{3 4}$ after $4 \mathrm{~h}$ compared with $95 \%$ after $43 \mathrm{~h}$ with $\mathbf{3 3}$ for the ATH of $m$-trifluoromethylacetophenone). An increase in water concentration from $15 \%$ to $51 \%$ did not decrease the reaction rate, as might be anticipated from the lower 2-propanol concentration.

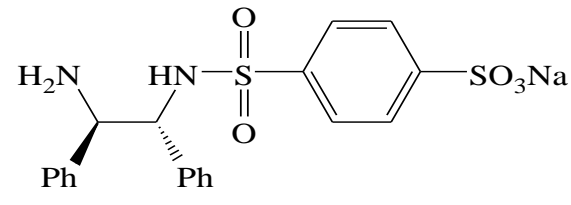

33

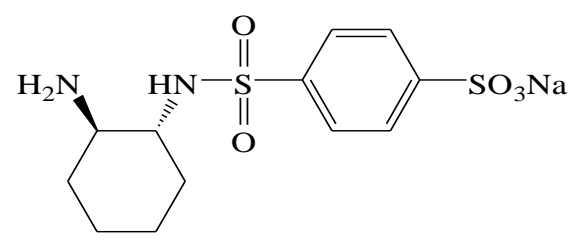

34

Scheme 26

In 2005 Xiao reported that the $\mathrm{Ir}^{\mathrm{III}}$ complex 32 displays good activity (99\% conversion after $1 \mathrm{~h}$ ) and excellent enantioselectivities (93\% e.e.) for the reduction of acetophenone in water by sodium formate, with no need for organic solvents or inert gas protection throughout the entire operation [42]. More recently, the same group studied in detail the reaction parameters for the ATH of ketones with complex (R,R)-31 [43]. They showed that the pH should be kept between 6.5 and 8.5 in order to maintain good activities and enantioselectivities. Under these conditions a large range of ketones, including heteroaryl ketones, have been successfully reduced with high yields and enantioselectivities (e.e. up to 97\%). However, in most cases the iridium complex (R,R)-31 is less active and enantioselective than its rhodium analogue. 
The iridium complex 35 of a camphor-based ligand was then tested for the ATH of a wide range of aryl alkyl and heteroaryl alkyl ketones under the same conditions with a substrate/catalyst ratio of 1000 (scheme 27). High conversions could be achieved for all ketones with a substrate/catalyst ratio of 1000 and in all cases the enantioselectivities are higher then $88 \%$ with a maximum of $98 \%$ for the ATH of acetophenone or 3-methoxy-acetophenone [44].

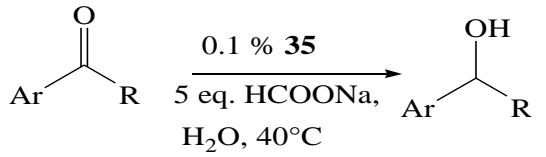

Scheme 27

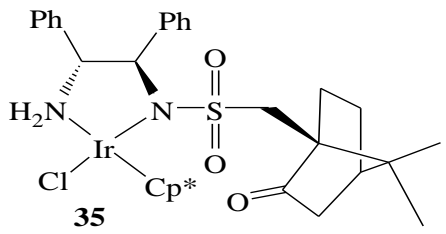

Iridium trimers 36 (see scheme 29) synthesized from natural L-prolinol have been used in the ATH of acetophenone with sodium formate [45]. Unlike $\mathbf{3 6} \mathbf{b}, \mathbf{3 6} \mathbf{a}$ showed good catalytic activities and enantioselectivities (e.e. up to 64\%).

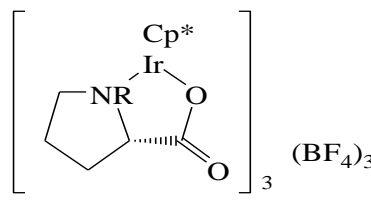

36a: $\mathrm{R}=\mathrm{H} ; \mathbf{3 6 b}: \mathrm{R}=\mathrm{Me}$

Scheme 28

In 2006 the group of Zhang described the synthesis of compounds $\mathbf{3 7}$ and $\mathbf{3 8}$ (Scheme 29), starting from the natural products quinine, quinidine, cinchonine and cinchonidine, and their use in the ATH of aromatic ketones in iridium catalytic systems using isopropanol as the hydrogen source [46,47]. Good to excellent yields (50-90\%) and enantioselectivities (72-97\%) were observed with a variety of aromatic ketones using $[\operatorname{Ir}(\mathrm{COD}) \mathrm{Cl}]_{2}$ as a metal precursor. Moreover, the Ir complex of $\mathbf{3 8}$ could be recovered in high yields with dilute hydrochloric acid and reused. In the asymmetric transfer hydrogenation of acetophenone, the enantioselectivity was maintained after six cycles [46]. 


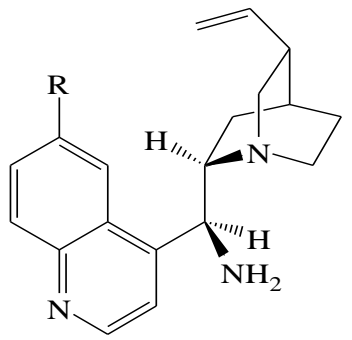

37a: $\mathrm{R}=\mathrm{OMe}$

37b: $\mathrm{R}=\mathrm{H}$

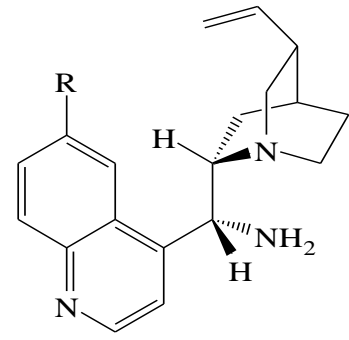

38a: $\mathrm{R}=\mathrm{OMe}$

38b: $\mathrm{R}=\mathrm{H}$

Scheme 29

\section{3. $\mathrm{N}, \mathrm{O}$ ligands}

Xiao et al. used complexes similar to 31 (see scheme 25), synthesized in situ from 1,2aminoalcohols and $\left[\mathrm{Cp}^{*} \mathrm{IrCl}_{2}\right]_{2}$ [48]. Good conversions could be achieved but enantioselectivities were low (e.e.=3-55\%). Sinou et al. used $\beta$-aminoalcohols 39 with $[\operatorname{Ir}(\mathrm{COD}) \mathrm{Cl}]_{2}$ in the ATH of acetophenone, with low activities and enantioselectivities (e.e. up to $30 \%$ for 39a, $\mathrm{R}=\mathrm{H}$ ), see scheme 30 [49].
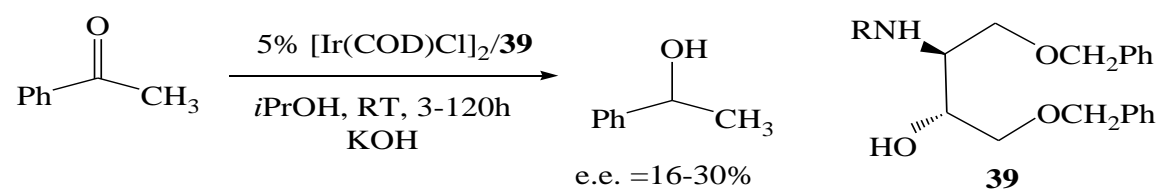

Scheme 30

\section{4. $\mathrm{N}, \mathrm{S}$ ligands}

Van Leeuwen has developed a new class of efficient catalytic systems [50]. Several chiral $N, S$-chelating ligands (40-55, Schemes 31-33) were synthesized and used as ligands in the iridium(I)-catalyzed reduction of ketones in formic acid or $i \mathrm{PrOH}$, both proving to be suitable hydrogen donors. Tested in the ATH of acetophenone with formic acid in the presence of $[\operatorname{Ir}(\mathrm{Cl}) \mathrm{COD}]_{2} / \mathrm{NEt}_{3}$, the amino-sulfide ligands 40-47 gave in some cases good conversion (98 $\%$ after $1 \mathrm{~h}$ at $60^{\circ} \mathrm{C}$ with $\mathbf{4 1 a}$ ) but the enantioselectivities were poor (5-18\%). 


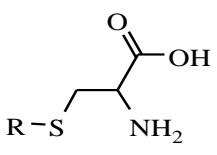

40a, $\mathrm{R}=\mathrm{Me}$ 40b, $\mathrm{R}=\mathrm{Bn}$ 40c, $\mathrm{R}=\mathrm{Tr}$

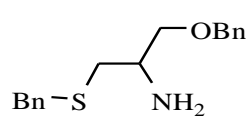

43<smiles>NC(CSc1ccccc1)C(O)(c1ccccc1)c1ccccc1</smiles>

45

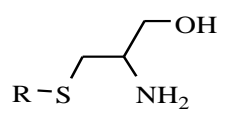

41a, $\mathrm{R}=\mathrm{Bn}$

41b, $\mathrm{R}=\mathrm{Tr}$

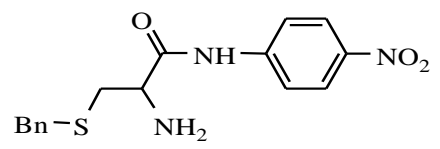

44

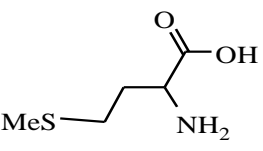

42<smiles>CC(C)(SBr)C(N)CO</smiles>

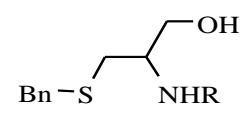

46

47a, $\mathrm{R}=\mathrm{Ts}$

47b, $\mathrm{R}=\mathrm{Boc}$

Scheme 31

The two diastereoisomeric ligands $\mathbf{4 8}$ which differ only by the configuration on sulphur have been tested in the ATH of acetophenone (scheme 32). The chirality on sulphur played a major role and with the matched diastereoisomer $\mathbf{4 8 b}$ a more active and more enantioselective catalytic system could be obtained (65\% e.e. in favour of S vs $27 \%$ e.e. in favour of R with $\mathbf{4 8 a}$, see scheme 32).

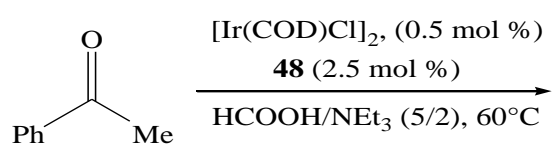

48a, $56 \%$ conversion after $1 \mathrm{~h}, 27 \%$ e.e. (R)

48b, $99 \%$ conversion after $30 \mathrm{~min}, 65 \%$ e.e. (S)

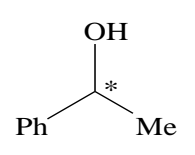

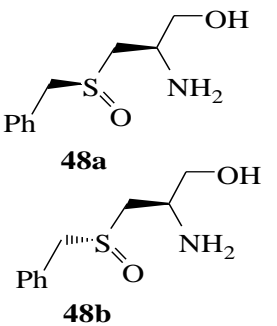

$48 b$

\section{Scheme 32}

For ligands 49-55, which contain an additional stereogenic carbon in the $\beta$ position in addition to the $\alpha$ position, the stereoselectivities in the ATH of acetophenone were moderate (23-65\% with the maximum e.e. for ligand 51). Catalytic activities were also moderate: quantitative conversions could only be obtained after $3 \mathrm{~h}$ with ligands $\mathbf{5 0}$ and $\mathbf{5 1}$. The introduction of the sulfoxide group (ligands $\mathbf{5 5 a}$ and $\mathbf{5 5} \mathbf{b}$ obtained by oxidation of compound 51) decreased considerably the conversion and the stereoselectivity of the reaction even for the matched diasteroisomer 55a (32\% e.e. (S) instead of $65 \%$ e.e. (S) with 51, see scheme 33). 

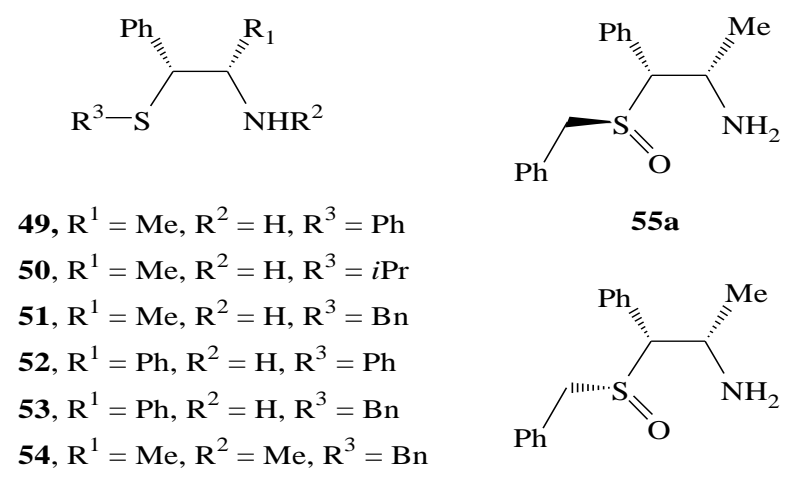

$55 \mathbf{a}$

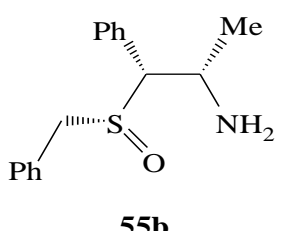

$55 b$

\section{Scheme 33}

Different $\operatorname{Ir}^{\mathrm{I}}$ precursors were tested: the enantioselectivity was only slightly affected but the best activities were obtained with $[\operatorname{Ir}(\mathrm{Cl})(\mathrm{COD})]_{2}$ and $\left[\operatorname{Ir}(\mathrm{COD})_{2}\right] \mathrm{BF}_{4}$. Decreasing the reaction temperature from 60 to $20{ }^{\circ} \mathrm{C}$ resulted in an enantioselectivity increase in all cases, with a maximum of $80 \%$ e.e. for ligand $48 \mathrm{~b}$ at $20^{\circ} \mathrm{C}$. Many other ketones were tested and the enantioselectivity was found to be significantly influenced by the electronic and steric properties of the substrate, increasing for substrates with bulkier substituents. The electronic properties were also shown to be important, higher e.e. being observed with more electronwithdrawing substituents. The maximum e.e. (97\%) was obtained with 1-naphtyl methyl ketone as a substrate using 2-propanol as hydrogen donor with ligand $\mathbf{5 3}$.

In 2001 the same group reported a comparison between the iridium(I)-amino sulfide complexes 51 and 53 and a biocatalytic system, using whole cells of the white-rot fungus Merulius tremellosus ono991, for the ATH of prochiral ketones. The two approaches were shown to be complementary. The biocatalytic approach is most suitable for the enantioselective reduction of chloro-substituted aryl ketones (with e.e. up to $88 \%$ ), whereas better results were obtained using the catalytic hydrogenation protocol in the reduction of $\alpha, \beta$-unsaturated compounds (e.e. up to $90 \%$ ) [51].

Camphor-based N,S ligands 56-59 (see scheme 34) in association with $[\operatorname{Ir}(\mathrm{COD}) \mathrm{Cl}]_{2}$ can catalyze the ATH of acetophenone but with moderate activities and enantioselectivities, the best e.e. (80\%) being obtained using ligand 56a [52]. 


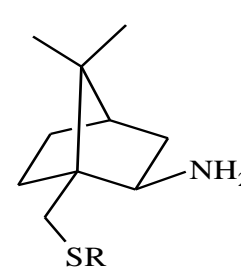

56a, $\mathrm{R}=\mathrm{Me}$

$56 b, R=E t$

56c, $\mathrm{R}=i \mathrm{Pr}$

56d, $\mathrm{R}=\mathrm{Bn}$

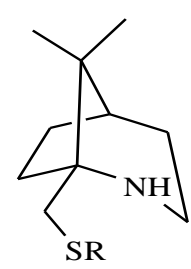

$57 \mathbf{a}, \mathrm{R}=\mathrm{Me}$

57b, $\mathrm{R}=\mathrm{Et}$

57d, $\mathrm{R}=\mathrm{Bn}$

57e, $\mathrm{R}=\mathrm{Ph}$

57f, $\mathrm{R}=\mathrm{H}$

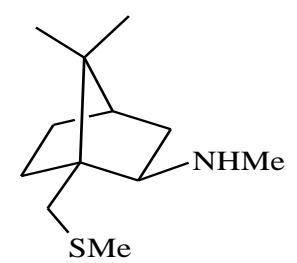

58

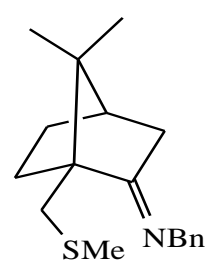

59

\section{Scheme 34}

\subsection{Other bidentate ligands}

Iridium complexes $\mathbf{6 0}$ of chiral NHC have been used in the ATH of aromatic ketones. Excellent activities could be obtained at $75^{\circ} \mathrm{C}$ but with low enantioselectivities (see scheme 35) [53].

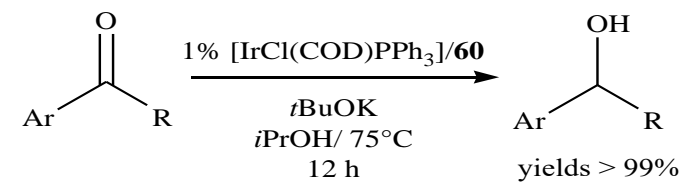

$\mathrm{Ar}=4-\mathrm{Me}-\mathrm{Ph}, \mathrm{R}=\mathrm{Me} \quad 14 \%$ e.e. for $\mathbf{6 0 a}, 52 \%$ for $\mathbf{6 0 b}$ $\mathrm{Ar}=3-\mathrm{MeO}-\mathrm{Ph}, \mathrm{R}=\mathrm{Me} \quad 6 \%$ e.e. for $60 \mathrm{a}$ $\mathrm{Ar}=\mathrm{Ph}, \mathrm{R}=\mathrm{Et}$

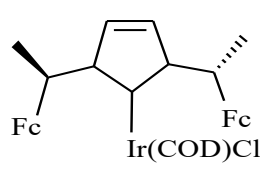

60a

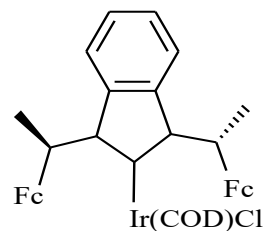

60b

\section{Scheme 35}

The amino-olefin complex $\mathbf{6 1}$ was used by Grützmacher et al in the ATH of acetophenone (see scheme 36) with good activities and enantioselectivities [54].

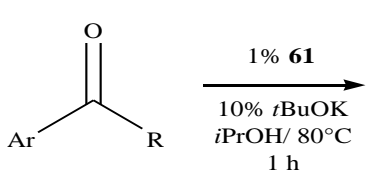

$1 \mathrm{~h}$

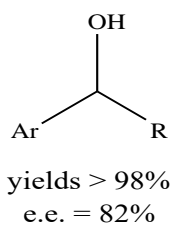

Scheme 36

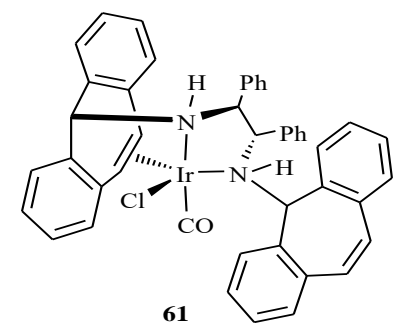

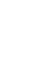


mixture of undefined isomers without free phosphine groups was obtained and applied to the ATH of various aromatic ketones using isopropanol as hydrogen source. The corresponding chiral alcohols could be obtained with high yields (up to 99.4\%) and excellent enantioselectivities (up to $99.0 \%$ for isopropyl methyl ketone or 1,1-diphenylacetone) under mild conditions. With propiophenone as substrate, a TON of 4780 and a TOF as high as 1593 $\mathrm{h}^{-1}$ at $55^{\circ} \mathrm{C}$ could be achieved. The analogous chiral iridium(I) complex with ligand 63 was also prepared and tested in the ATH of acetophenone, but the reaction was very slow under the same conditions, $(R)$-1-phenylethanol being obtained only in $39.8 \%$ yield and $39.5 \%$ e.e. after $48 \mathrm{~h}$. These results indicate that the NH functions are responsible for the high activity, possibly stabilizing a catalytic intermediate [55].

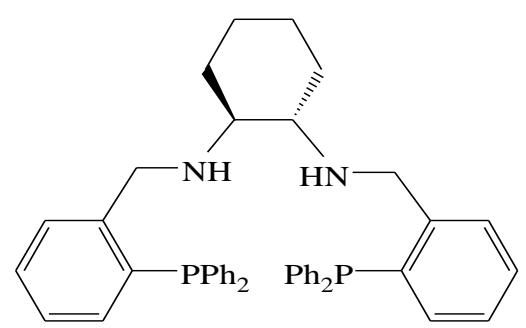

62

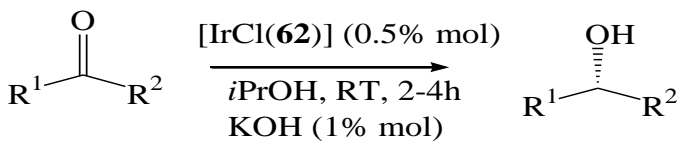

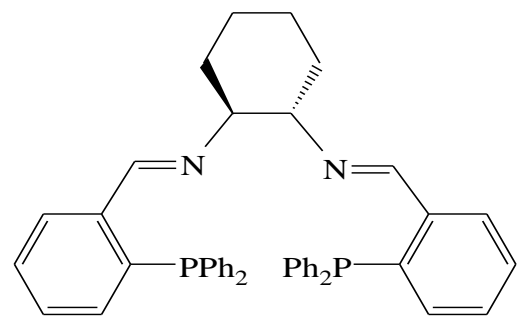

63

\section{Scheme 37}

Gao et al. have also shown that complexes obtained in situ from $\left[\mathrm{IrHCl}_{2}(\mathrm{COD})\right]_{2}$ and the same ligand 62 have a remarkable ATH catalytic activity under ambient conditions and afford improved enantioselectivities in certain cases (for instance, the ATH of $t$-butyl phenyl ketone yields $93 \%$ e.e. instead of $82 \%$ with $\operatorname{IrCl}(62))$. The amount of catalyst could be decreased to the level of $0.01-0.05 \%$. For instance, the alcohol derived from 1,1-diphenylacetone could be obtained with up to $99 \%$ e.e. in $89 \%$ yield after $63 \mathrm{~h}$ with a substrate-to-catalyst molar ratio of 10000:1. In addition, the reaction was neither affected by air nor by the addition of water [56]. This catalytic system is also efficient in the asymmetric transfer hydrogenation of aromatic ketones with $\mathrm{HCOONa}$ in water, giving the corresponding optically active alcohols again in 
high yields and excellent e.e. (up to 99\%) [57]. In the presence of a different metal precursor, $\left[\mathrm{IrH}(\mathrm{CO})\left(\mathrm{PPh}_{3}\right)_{3}\right]$, ligand 62 afforded a $90 \%$ e.e. and a $97 \%$ yield after $0.5 \mathrm{~h}$ in isopropanol at $75^{\circ} \mathrm{C}$ for the ATH of propiophenone, without any base. Different other ketones were tested and the results were very similar, with excellent yields and e.e. (up to $99 \%$ and 97\%, respectively) [58]. The reaction could be also carried out in a isopropanol/water mixture using $\left[\mathrm{IrCl}(\mathrm{COD})\left(\mathrm{Ph}_{3} \mathrm{P}\right)\right]$ and a water-soluble analogue of $\mathbf{6 2}$ prepared by sulfonation of $\mathbf{6 2}$ with oleum, but with with reduced catalytic activities and sometimes slightly lower enantioselectivities [59].

Using again 1,2-cyclohexanediamine as a source of chirality, Gao et al. tested tetraaza ligands 64 and 65 in the ATH of propiophenone (scheme 38). Catalytic systems based on 64 proved to be more active and more enantioselective than the systems with $\mathbf{6 5}$ (e.e. up to $67 \%$ for 64, 56\% for 65) [60]. High level of enantioselectivities could be obtained in the ATH of various aromatic ketones using 64 and $\left[\mathrm{IrHCl}_{2}(\mathrm{COD})\right]_{2}$ as a source of iridium (see scheme 32 ).

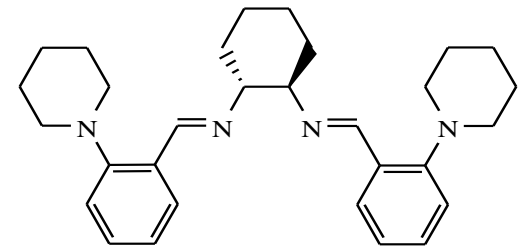

64

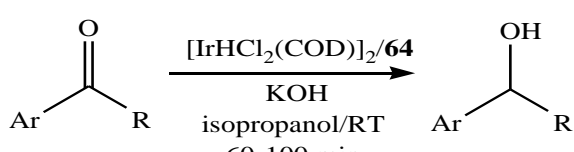

$60-100 \mathrm{~min}$

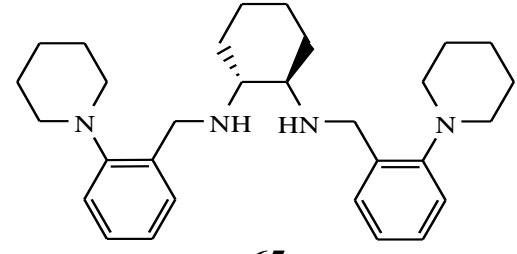

65

$\mathrm{Ar}=\mathrm{Ph}, \mathrm{R}=\mathrm{Me} \quad 76 \%$ e.e. $\mathrm{Ar}=\mathrm{Ph}, \mathrm{R}=\mathrm{Et} \quad 80 \%$ e.e. $\mathrm{Ar}=\mathrm{Ph}, \mathrm{R}=n \mathrm{Pr} \quad 88 \%$ e.e. $\mathrm{Ar}=\mathrm{Ph}, \mathrm{R}=\mathrm{iPr} \quad 64 \%$ e.e. $\mathrm{Ar}=\mathrm{Ph}, \mathrm{R}=n \mathrm{Bu} \quad 91 \%$ e.e. $\mathrm{Ar}=2$-tolyl, $\mathrm{R}=\mathrm{Me} \quad 90 \%$ e.e.

Scheme 38

Gao and coworkers used also tetradentate S,N,N,S ligands 66 in the ATH of various aromatic ketones in isopropanol in air with good activities and very good enantioselectivities (see scheme 39) [61].
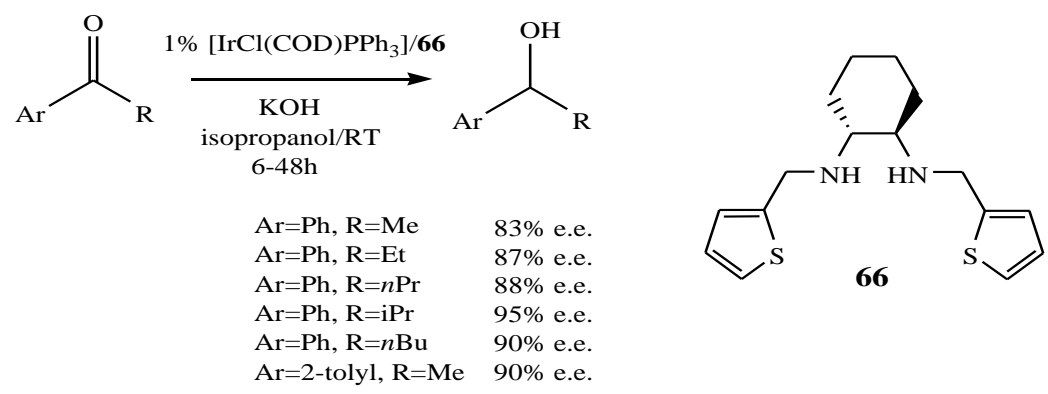


\section{Scheme 39}

$\mathrm{N}, \mathrm{N}, \mathrm{O}, \mathrm{O}$ macrocycle $\mathbf{6 7}$ in presence of $[\mathrm{IrCl}(\mathrm{COD})]_{2}$ could also been successfully used in the ATH of phenyl ethyl ketone (see scheme 40) [62].

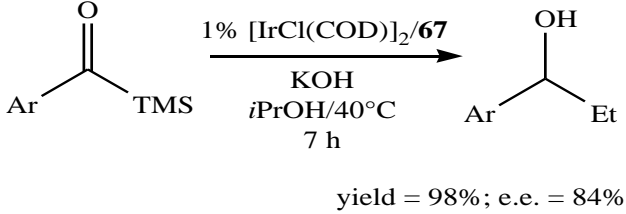

yield $=98 \% ;$ e.e. $=84 \%$

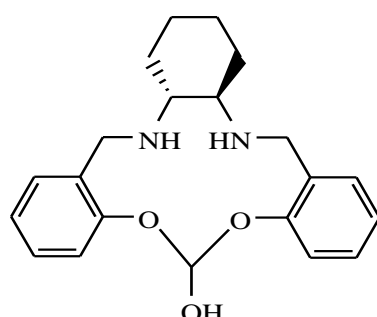

67

Scheme 40

Various neutral or cationic iridium(I) and (III) complexes of PYBOX ligands 68 (see scheme 41) have been tested in the ATH of aromatic ketones [63]. For each PYBOX ligand, iridium(III) complexes are more catalytically active and more enantioselective than the corresponding $\operatorname{Ir}(\mathrm{I})$ complexes. The counteranion of cationic complexes proved to have a major influence on catalytic performances (rate and e.e.). The best results were obtained with $\left[\mathrm{IrCl}_{2}(\mathbf{6 8 a})(\mu-\mathrm{Cl}) \mathrm{Ag}\right]\left[\mathrm{BF}_{4}\right]$ (see scheme 41).
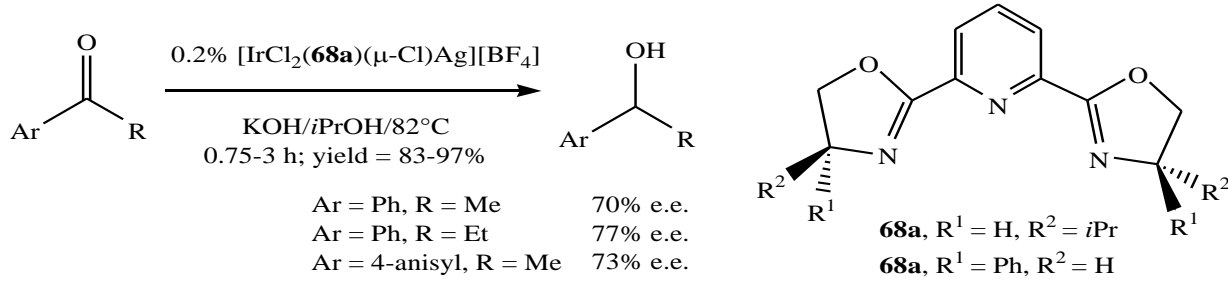

\section{Scheme 41}

Zhang and coworkers used ferrocenyl diphosphine-diimine 69 in association with $[\operatorname{Ir}(\mathrm{COD}) \mathrm{Cl}]_{2}$ and $\mathrm{KOH}$ in the ATH of acetophenone [64]. The catalytic systems exhibited moderate activities and enantioselectivities (up to $49 \%$ e.e. for 69a, scheme 42).
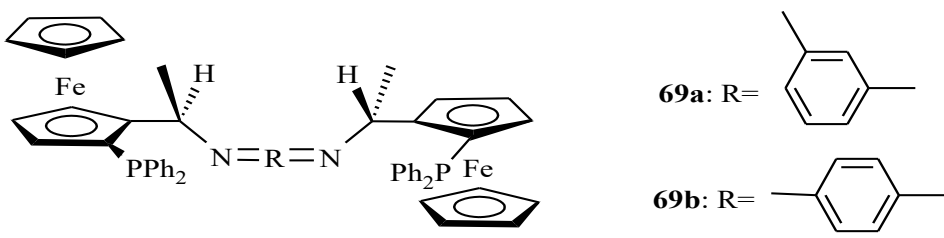

Scheme 42 
Stradiotto et al. tested several P,N,P and P,N,N,P ligands in the ATH of acetophenone. Good activities but low enantioselectivities (e.e. $<50 \%$ ) were obtained with TANIAPHOS 70. MANDYPHOS 71b was even worse with low activities and enantioselectivities (e.e. up to 37\%). However, good yields and e.e. could be achieved with MANDYPHOS 71a for a large range of ketones, especially for the very hindered $\mathrm{PhC}(\mathrm{O}) t \mathrm{Bu}$ (see scheme 43) [65].
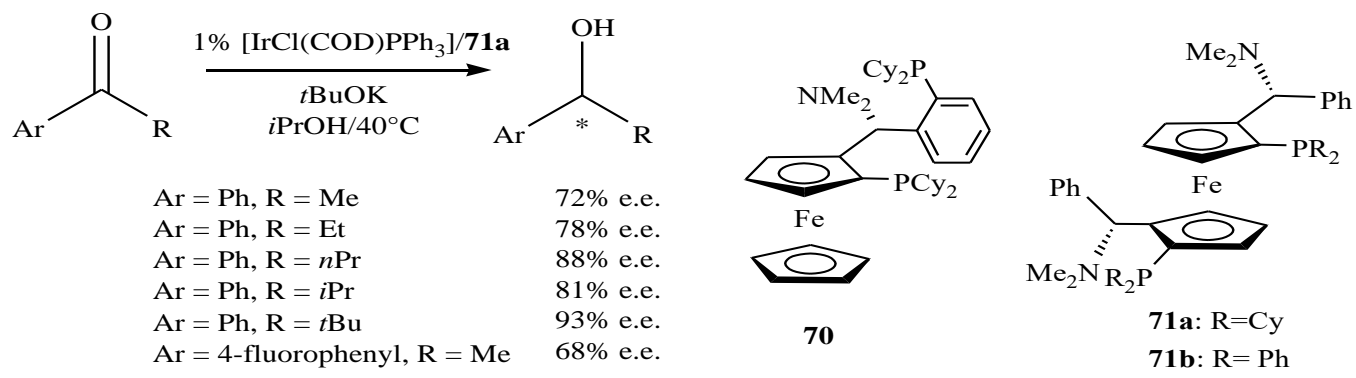

Scheme 43

\section{Asymmetric hydrogenation (AH) of ketones with iridium}

Although the asymmetric transfer hydrogenation of ketones with iridium complexes has been well studied and developed, the use of molecular $\mathrm{H}_{2}$ as hydrogen donor has been much less explored.

\section{1. $P, P$ ligands}

One of the first examples of $\mathrm{AH}$ of ketones in the presence of iridium under $\mathrm{H}_{2}$ was described by Monsanto [66] in 1975. The asymmetric hydrogenation of alkanones was accomplished with bis[cyclohexyl(o-methoxyphenyl)methylphosphine]-1,5-cyclooctadieneiridium(I) tetrafluoroborate $\mathbf{7 2}$ (scheme 44) or with analogous catalysts but the enantioselectivities were very poor. In 1990, Graziani [67] tested bis or mono(diphosphine) iridium complexes 73, 74 in the $\mathrm{AH}$ of $\mathrm{PhCOCH}_{2} \mathrm{NRR}^{1}\left[\mathrm{R}=\mathrm{CH}_{2} \mathrm{Ph}, \mathrm{R}^{1}=\mathrm{Me}, \mathrm{CH}_{2} \mathrm{Ph}\right.$; $\mathrm{RR}^{1}=$ $\left.\left(\mathrm{CH}_{2}\right)_{5}\right]$ at $60^{\circ} \mathrm{C}$ and $70 \mathrm{~atm}$ in benzene or toluene to give $R-(+)-\mathrm{HOCHPhCH}_{2} \mathrm{NRR}^{1}$ with $>99 \%$ conversion and $21-30 \%$ e.e. 


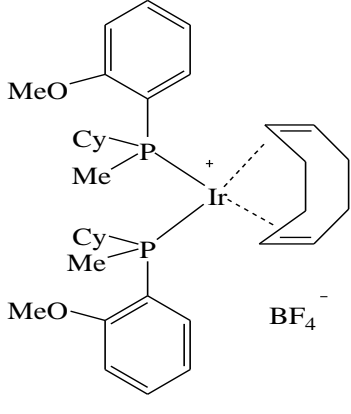

72

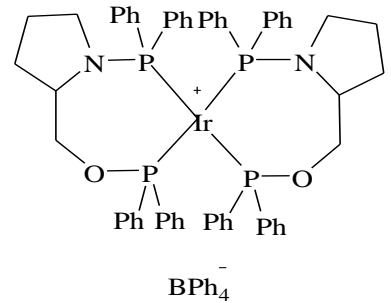

73

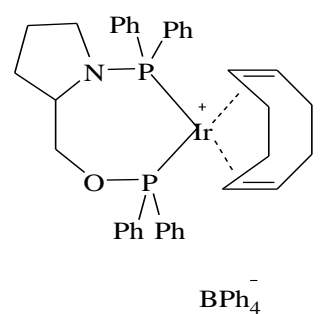

74

Scheme 44

Takaya et al. used successfully [(BINAP) $\operatorname{Ir}(\mathrm{COD})] \mathrm{BF}_{4}$ and [(H8-BINAP) $\left.\operatorname{Ir}(\mathrm{COD})\right] \mathrm{BF}_{4}$ in presence of an achiral phosphine 75 in the $\mathrm{AH}$ of various ketones (see scheme 45) [68,69,70]. [(BINAP) $\operatorname{Ir}(\mathrm{COD})] \mathrm{BF}_{4}$ was more efficient for most substrates (scheme 45$)$ but $\left[\left(\mathrm{H}_{8}-\right.\right.$ BINAP) $\operatorname{Ir}(\mathrm{COD}) \mathrm{BF}_{4}$ was more selective in the $\mathrm{AH}$ of $\mathbf{7 6}$ (scheme 45). 
<smiles>c1ccc(-c2ccc3c(c2-c2c(-c4ccccc4)ccc4c2CCCC4)CCCC3)cc1</smiles>

$\mathrm{H}_{8}$-BINAP<smiles>CN(C)c1ccccc1-c1ccccc1</smiles>

75<smiles>[X]c1cc([R])cc(C(=O)CCC)c1</smiles><smiles>CC(C(=O)O)C(=O)O</smiles><smiles>[R]c1cc([R])c([X])c(C2CCCCC2)c1</smiles>

yields $=72-88 \%$

e.e. $=84-95 \%$; $\operatorname{Ir}^{*}=[(\mathrm{BINAP}) \operatorname{Ir}(\mathrm{COD})] \mathrm{BF}_{4}$

$\mathrm{R}=\mathrm{R}^{\prime}=\mathrm{CH}_{3}, \mathrm{X}=\mathrm{CH}_{2}, 95 \%$ e.e.; $\mathrm{R}=\mathrm{OMe}, \mathrm{R}^{\prime}=\mathrm{H}, \mathrm{X}=\mathrm{CH}_{2}, 95 \%$ e.e.;

$R=R^{\prime}=H, X=O, 93 \%$ e.e.; $R=R^{\prime}=H, X=S, 84 \%$ e.e.<smiles>[R]C(=O)c1ccccc1</smiles>

$0.5-1 \% \operatorname{Ir} * / 75$

54-61 bars $\mathrm{H}_{2}$

dioxane- $\mathrm{MeOH}$

$60-120^{\circ} \mathrm{C}, 22-210 \mathrm{~h}$<smiles>[R]C(O)c1ccccc1</smiles>

yields $=3-84 \%$

e.e. $=84-95 \%$; Ir* $=[($ BINAP $) \operatorname{Ir}(C O D)] B^{4}$

$\mathrm{R}=\mathrm{Me}: 54 \%$ e.e.; $\mathrm{R}=n \mathrm{Bu}: 3 \%$ e.e. $; \mathrm{R}=i \operatorname{Pr}: 84 \%$ e.e.

$\mathrm{R}=$ cyclopentyl: $73 \%$ e.e.; $\mathrm{R}=$ cyclohexyl: $79 \%$ e.e.
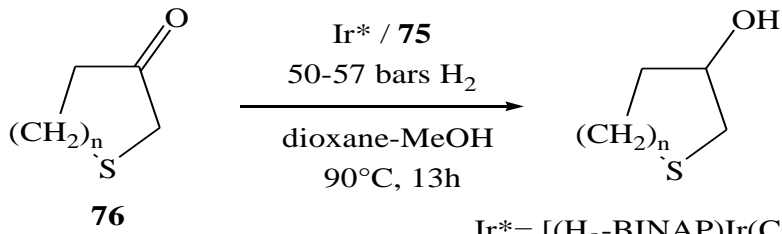

$90^{\circ} \mathrm{C}, 13 \mathrm{~h}$

is

$\operatorname{Ir}^{*}=\left[\left(\mathrm{H}_{8}-\mathrm{BINAP}\right) \operatorname{Ir}(\mathrm{COD})\right] \mathrm{BF}_{4}$

76a $(n=1)$ : yield $=87 \%$, e.e. $=75 \% ; 76 b(n=2):$ yield $=94 \%$, e.e. $=70 \%$

\section{Scheme 45}

Iridium complexes, synthesized from chiral diphosphines (BINAP or MeO-BIPHEP) and $\operatorname{Ir}(\mathrm{COD})_{2} \mathrm{Cl}$, were successfully used in the dynamic kinetic resolution of $\alpha$-amino- $\beta$ ketoesters by hydrogenation. After an optimisation with the MeO-BIPHEP complex, a very efficient catalytic system could be obtained with good activities, very high diastereoselectivities and high eantioselectivities (see scheme 46) [71]. 


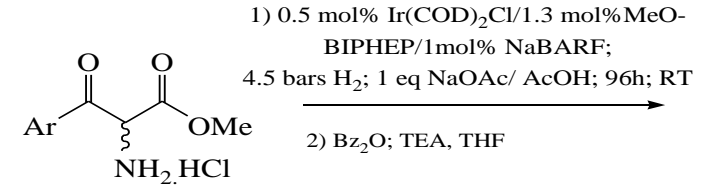

$\mathrm{Ar}=$ aromatic and heteoaromatic rings

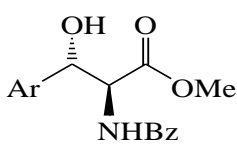

Yields $=61-100 \%$

anti:syn $>99 / 1$

$\mathrm{ee}=84-93 \%$

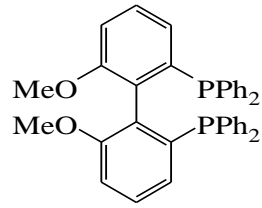

MeO-BIPHEP

\section{Scheme 46}

\section{2. $\mathbf{N}, \mathbf{N}$ ligands}

In 1996, Lemaire et al. started a study on the AH of ketones with neighbouring functional groups using iridium complexes of $\mathrm{N}, \mathrm{N}$ ligands $[33,72,73]$. The best results were obtained with 77a in THF for the AH of methyl phenylglyoxylate (e.e. up to 80\%) [74]. The same authors studied also the $\mathrm{AH}$ of acetophenone with iridium complexes containing the same $C 2$ symmetric diamine ligands 77 (Scheme 47). E.e. values of up to $63 \%$ were observed when the reaction was performed in THF. The introduction of different hydrophilic groups on the ligand allowed the asymmetric hydrogenation of acetophenone in aqueous media but lower activities and enantioselectivities were observed relative to the reaction in THF. The use of such ligands allowed catalyst recovery without loss of activity and enantioselectivity in at least four hydrogenation cycles [74].

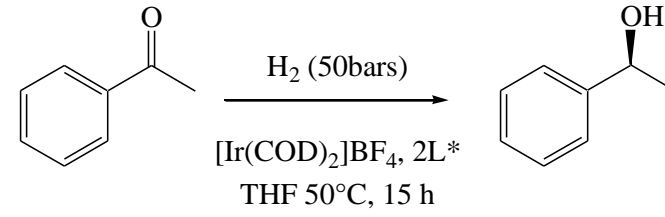

$71 \%$ yield, $63 \%$ e.e., $77 \mathbf{a}$ $44 \%$ yield, $46 \%$ e.e., $77 b$ $50 \%$ yield, $61 \%$ e.e., $77 \mathrm{c}$ $43 \%$ yield, $51 \%$ e.e., $77 d$

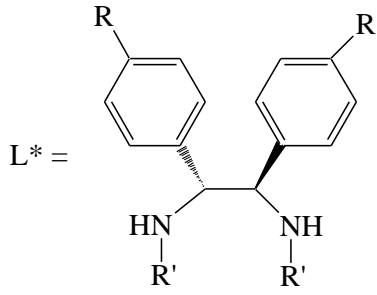

77a, $\mathrm{R}=\mathrm{H}, \mathrm{R}^{\prime}=\mathrm{Me}$

77b, $\mathrm{R}=\mathrm{OMe}, \mathrm{R}^{\prime}=\mathrm{Me}$

77c, $\mathrm{R}=\mathrm{OH}, \mathrm{R}^{\prime}=\mathrm{Me}$

77d, $\mathrm{R}=\mathrm{O}-\left(\mathrm{C}_{2} \mathrm{H}_{4} \mathrm{O}\right)_{3} \mathrm{CH}_{3}, \mathrm{R}^{\prime}=\mathrm{Me}$

Scheme 47

The same group [75] prepared a water-soluble version of $N, N$-dimethyl-1,2diphenylethane-1,2-diamine by introduction of phosphonic acid moieties on the para position of the aromatic rings (78, Scheme 48). Preliminary investigations under biphasic conditions showed that iridium complexes of this ligand compared well with the homogeneous counterpart for the asymmetric hydrogenation of ketones but with noticeably higher reaction rates. For the 
$\mathrm{AH}$ of acetophenone in $\mathrm{MeOH}$ at 45 atm of $\mathrm{H}_{2}$, total conversion and enantioselectivities varying between 34 and 55\% were obtained as a function of the metal/ligand/substrate ratio. Different other ketones were tested under the same conditions and a maximum of $72 \%$ e.e. was obtained for the AH of phenyl $t$-butyl ketone.

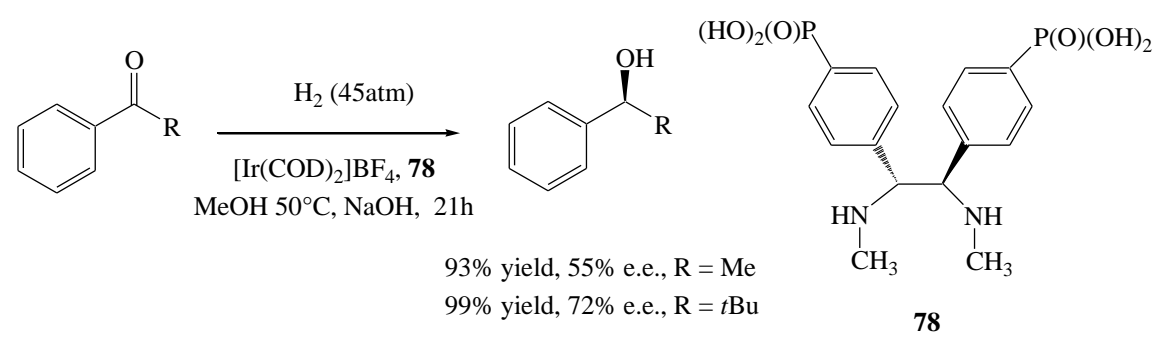

Scheme 48

Ohkuma et al. used DPEN-based complexes $\mathbf{7 9}$ and 31, as a catalyst for the AH of various $\alpha$-hydroxyketones [76]. The best results were obtained with complex 79 yielding diols in good yields and with high enantioselectivities for a large variety of substrates (scheme 49) except for electron-rich substrates like (4-methoxyphenyl)(hydroxymethyl)ketone which could not be reduced at all.
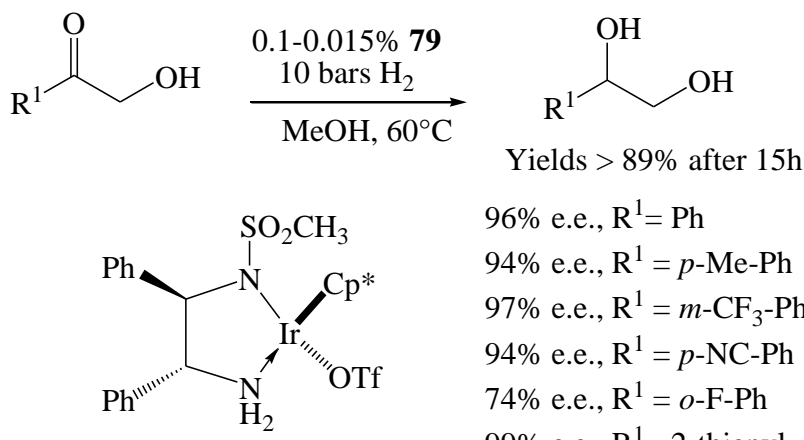

$$
\begin{aligned}
& 96 \% \text { e.e., } \mathrm{R}^{1}=\mathrm{Ph} \\
& 94 \% \text { e.e., } \mathrm{R}^{1}=p-\mathrm{Me}-\mathrm{Ph} \\
& 97 \% \text { e.e., } \mathrm{R}^{1}=m-\mathrm{CF}_{3}-\mathrm{Ph} \\
& 94 \% \text { e.e., } \mathrm{R}^{1}=p-\mathrm{NC}-\mathrm{Ph} \\
& 74 \% \text { e.e., } \mathrm{R}^{1}=o-\mathrm{F}-\mathrm{Ph} \\
& 99 \% \text { e.e., } \mathrm{R}^{1}=2 \text {-thienyl } \\
& 80 \% \text { e.e., } \mathrm{R}^{1}=\mathrm{CH}_{3}
\end{aligned}
$$

\section{Scheme 49}

A mesoporous silica-supported chiral iridium catalyst $\mathbf{8 0}$ was prepared by $\mathrm{Li}$ and coworkers by grafting $\left\{\operatorname{IrCl}\left[\mathrm{PPh}_{2}\left(\mathrm{CH}_{2}\right)_{2} \mathrm{Si}(\mathrm{OEt})_{3}\right]_{2}[(\mathrm{R}, \mathrm{R})-\mathrm{DPEN}]\right\}$ on $\mathrm{SBA}-15$ silica [77]. Various aromatic ketones have been reduced to the corresponding alcohols with high yields and enantioselectivities (scheme 50). The catalyst could be recycled and reused with only a slight decrease in activity and enantioselectivity (from $99 \%$ e.e. in run 1 to $88 \%$ e.e. in run 6; see scheme 50). 


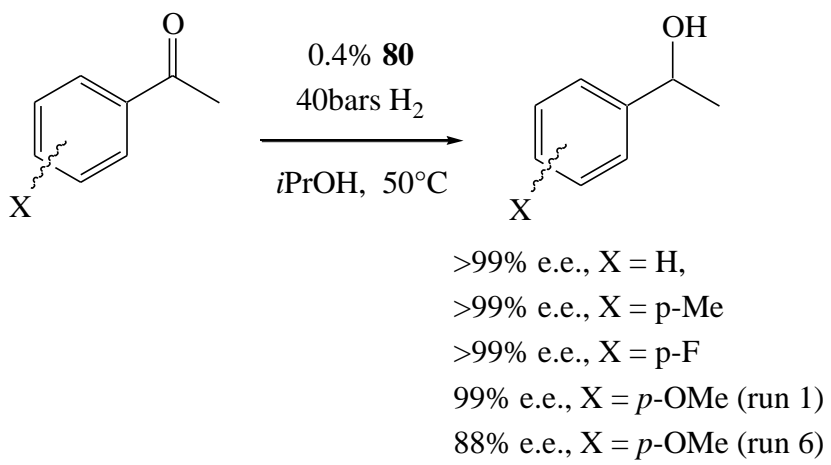

Scheme 50

Iridium deposed on silica in presence of cinchonidine was used in the heterogenous hydrogenation of various ketones. Good enenantioselectivities could be obtained (1-phenyl-1,2 propanedione: ee up to 70\%; ethyl pyruvate: ee up to 75\%, acetophenone: ee up to 33\%) [78]. Silica modified by reaction with $\mathrm{H}_{2} \mathrm{IrCl}_{6}$ and $\mathrm{PPh}_{3}$ was used as source of iridium together to chiral diamines $\mathbf{3 7 b}$ and $\mathbf{3 8 b}$ in the $\mathrm{AH}$ of various aromatic ketones by Chen and co-workers [79]. Activities were moderate but high enantioselectivities were observed (e.e. up to $96 \%$, see scheme 51).<smiles>[X]c1ccc(C(C)=O)cc1</smiles>

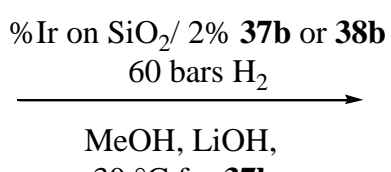
$30{ }^{\circ} \mathrm{C}$ for $\mathbf{3 7 b}$ $40^{\circ} \mathrm{C}$ for $\mathbf{3 8 b}$

$\mathrm{X}=\mathrm{H}: \mathbf{8 8 \%}$ e.e. for $\mathbf{3 7 b}, \mathbf{7 4 \%}$ for for $\mathbf{3 8 b}$

$\mathrm{X}=o$-F: $86 \%$ e.e. for $\mathbf{3 7 b}, 77 \%$ for for $\mathbf{3 8 b}$

$\mathrm{X}=o-\mathrm{Cl}: 96 \%$ e.e. for $\mathbf{3 7 b}, 86 \%$ for for $\mathbf{3 8 b}$

$\mathrm{X}=o$-Br: $92 \%$ e.e. for $\mathbf{3 7 b}, 90 \%$ for for $\mathbf{3 8 b}$

$\mathrm{X}=o$-OMe: $94 \%$ e.e. for $\mathbf{3 7 b}, 95 \%$ for $\mathbf{3 8 b}$

$\mathrm{X}=o-\mathrm{CF}_{3}: 81 \%$ e.e. for $\mathbf{3 7 b}, 83 \%$ for for $\mathbf{3 8 b}$

$\mathrm{X}=p$-OMe: $87 \%$ e.e. for $\mathbf{3 7 b}, 76 \%$ for $\mathbf{3 8 b}$

\section{Scheme 51}

A similar strategy was used by the same authors with other cinchona alkaloids like cinchonine, cinchonidine, quinine, O-methyl cinchonidine or O-acetyl cinchonidine instead of $\mathrm{PPh}_{3}$ for the stabilisation of iridium on silica surface [80]. After optimisation, an e.e. of $80 \%$ could be obtained in the $\mathrm{AH}$ of acetophenone in the presence of (1S,2S)-DPEN and LiOH in $\mathrm{MeOH}$ at $333 \mathrm{~K}$. The catalysts could be recycled and reused in 8 successive runs with only a slight loss in activities and enantioselectivities (e.e. $=56 \%$ in run 8 instead of $71 \%$ in run 1 ). 
Complexes obtained from tetradentate ligands $\mathbf{8 1}$ and $\mathbf{8 2}$ (scheme 52) and different salts of $\mathrm{Ru}(\mathrm{II}), \mathrm{Rh}(\mathrm{III})$ and $\mathrm{Ir}(\mathrm{III})$ were tested in the $\mathrm{AH}$ of acetophenone. Mixtures of the products resulting from ketone or aromatic ring reduction were obtained except in the case of $\operatorname{Ir}^{\mathrm{III}}$ compounds, which yielded only 1-phenylethanol. However, the observed enantioselectivities were moderate (e.e. up to $43 \%$ with $\mathbf{8 1}$ ) [81].<smiles>[AlH2]N[C@H](c1ccccc1)[C@@H](NCCNC(c1ccccc1)c1ccccc1)c1ccccc1</smiles>

81<smiles>[AlH2]N[C@H](c1ccccc1)[C@@H](NCCCNC(c1ccccc1)c1ccccc1)c1ccccc1</smiles>

82

Scheme 52

The same authors tested several bidentate ligands 83 based on diphenylethylene-1,2diamine. Ligands 83a-83e were identified as the most successful in the $\mathrm{AH}$ of various ketones (e.e. $=17-84 \%$, scheme 53) [81].

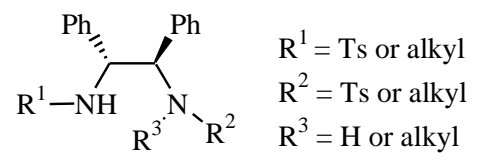

83<smiles>[3H]N[C@H](c1ccccc1)C(NCc1ccccc1)c1ccccc1</smiles>

83a<smiles>[3H]N[C@H](c1ccccc1)C(NCC)c1ccccc1</smiles>

83b<smiles>[3H]N[C@H](c1ccccc1)[C@@H](NCCCc1ccccc1)c1ccccc1</smiles>

83c<smiles>[Al]NC(c1ccccc1)C(NCCc1ccccc1)c1ccccc1</smiles><smiles>[3H]N[C@H](c1ccccc1)C(NCCC)[C@@H](c1ccccc1)C(C)(C)C</smiles><smiles>CC(=O)c1ccc(C)cc1</smiles>

e.e. $=63 \%$ with $83 \mathrm{c}$ e.e. $=63 \%$ with $\mathbf{8 3 d}$ e.e. $=66 \%$ with $83 \mathrm{e}$<smiles>CC(C)CC(=O)c1ccccc1</smiles>

e.e. $=68 \%$ with $\mathbf{8 3 b}$ e.e. $=73 \%$ with $83 \mathrm{e}$<smiles>CC(=O)c1cccc(C)c1</smiles>

e.e. $=61 \%$ with $\mathbf{8 3 c}$ e.e. $=68 \%$ with $83 \mathrm{e}$<smiles>CC(=O)c1cc(C)ccc1C</smiles>

e.e. $=83 \%$ with $\mathbf{8 3 e}$

Scheme 53 


\subsection{Other ligands}

In 2004, Götz and Dahlenburg [82] reported the synthesis and use of chiral $P, N$-chelated $\mathrm{Ir}^{\mathrm{I}}$ complexes of the general type $\left[(\mathrm{COD}) \operatorname{Ir}\left(\mathrm{P}-\mathrm{NR}^{1} \mathrm{R}^{2}\right)\right] \mathrm{BF} 4(\mathbf{8 4 - 8 6})$ in the $\mathrm{AH}$ of ketones (scheme 54). In the presence of an alkaline or amine base, all complexes catalyzed the direct hydrogenation of alkyl aryl ketones to the corresponding 1-phenylalkanols in methanol under $\mathrm{H}_{2}$ (10-50 bar) between 25 and $50{ }^{\circ} \mathrm{C}$. The $\mathrm{AH}$ of acetophenone occurred with modest to moderate enantioselectivity (30-55\% e.e.) in the presence of iridium complex $\mathbf{8 6}(R, R)$ and different bases. In all cases the enantioselectivities obtained in the presence of $\mathrm{KOH}$ were higher then with (-)sparteine (19-55\% and 4-47\% respectively). Other alkyl aryl ketones were tested with $\mathbf{8 6}(R, R)$ as catalyst and a maximum of $68 \%$ e.e. was obtained for the AH of phenyl 3chloropropyl ketone.

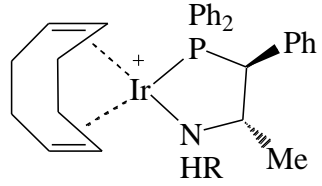

84a $(S, S), \mathrm{R}=\mathrm{H}$ $\mathbf{8 4 b}(S, S), \mathrm{R}=\mathrm{CH}_{2} \mathrm{Ph}$ $\mathbf{8 4 c}(S, S), \mathrm{R}=\mathrm{CHMe}_{2}$

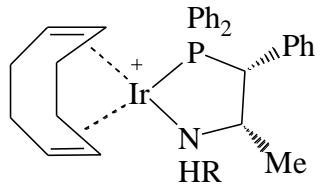

85a $(R, S), \mathrm{R}=\mathrm{Me}$ 85b $(R, S), \mathrm{R}=\mathrm{CHMe}_{2}$

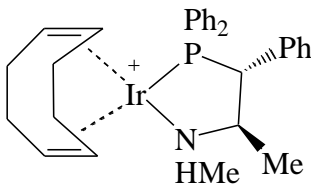

$86(R, R)$<smiles>[R]C(=O)c1ccccc1</smiles>

\section{Scheme 54}

The same group also tested several Ir III complexes bearing chiral diamines, diphosphines, or a combination of both (87-90, scheme 55) [83]. All complexes are catalytically active in the AH of acetophenone. The dihydride $\mathbf{8 7}$ and $\mathbf{8 8}$ are less active and poorly enantioselective (e.e. $<30 \%$ ), whereas good activities and enantioselectivities were obtained with complexes 89-90 in particular with 90a, used as a preformed complex or obtained in situ from $\mathbf{8 9}$ and (R,R)DPEN (e.e. up to 84\%). 
<smiles>[R16][Y]([R16])([H])[NH2+][C@@H]1CCCC[C@H]1N</smiles>

87a $: \mathrm{R}=\mathrm{Ph}$ 87b : $\mathrm{R}=i \mathrm{Pr}$<smiles>[R17][Y17]([R17])([R7])Nc1ccc2ccccc2c1-c1c(N)ccc2ccccc12</smiles>

88a $: \mathrm{R}=\mathrm{Ph}$

88b : $\mathrm{R}=i \mathrm{Pr}$ 88c : $\mathrm{R}=\mathrm{Cy}$

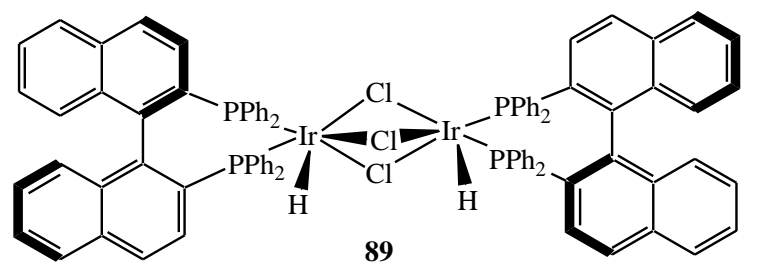<smiles>[R]C1([R])N[IH-](c2ccccc2-c2ccc3ccccc3c2-c2ccc3ccccc3c2-c2ccccc2)NC1([R])[R]</smiles>

90a : $\mathrm{R}^{1}=\mathrm{R}^{3}=\mathrm{H} ; \mathrm{R}^{2}=\mathrm{R}^{4}=\mathrm{Ph}$

90b: $\mathrm{R}^{1}=\mathrm{R}^{3}=\mathrm{H} ; \mathrm{R}^{2}, \mathrm{R}^{4}=\left(\mathrm{CH}_{2}\right)_{4}$

90c : $\mathrm{R}^{1}=\mathrm{R}^{2}=\mathrm{R}^{3}=\mathrm{R}^{4}=\mathrm{CH}_{3}$

\section{Scheme 55}

In 2007, we [84] showed that the iridium complexes 91 and 92 (Scheme 56) bearing planar-chiral ferrocenyl phosphine-thioether ligands are active in the $\mathrm{AH}$ of simple ketones. Different additives were tested for the hydrogenation of acetophenone in isopropanol at 30 bars $\mathrm{H}_{2}$, and total conversion was obtained with strong bases like $\mathrm{NaOMe}, \mathrm{KO} t \mathrm{Bu}$ or $\mathrm{KOH}$. The catalytic activities are especially high (TON up to 915 and TOF up to $c a .250 \mathrm{~h}^{-1}$ at $25^{\circ} \mathrm{C}$ ). The AH of acetophenone gave $43-77 \%$ e.e. at RT, the best value being obtained with the complex 91c having benzyl as substituent on the sulphur atom. Various other ortho, meta and para substituted acetophenones were studied and again complex 91c showed the best enantioselectivities (for instance, $76 \%$ e.e. for the $\mathrm{AH}$ of 4 -chloroacetophenone). When the reaction was carried out at $10^{\circ} \mathrm{C}$, much higher enantioselectivities (up to $>99 \%$ for 4 fluoroacetophenone) were obtained while the catalytic activities remained acceptably high. The reaction also takes place in toluene, whereas no activities were recorded in alcohol solvents in the absence of molecular $\mathrm{H}_{2}$. 


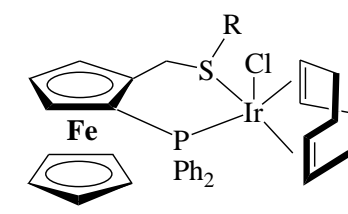

91a, $\mathrm{R}=\mathrm{Ph}$ 91b, $\mathrm{R}=\mathrm{Et}$ 91c, $\mathrm{R}=\mathrm{Bz}$

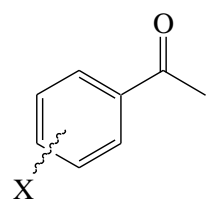

$77 \%$ e.e., $\mathrm{X}=\mathrm{H}$,

$56 \%$ e.e., $\mathrm{X}=o-\mathrm{Cl}$,

$47 \%$ e.e., $\mathrm{X}=o-\mathrm{F}$

$72 \%$ e.e., $\mathrm{X}=m-\mathrm{Me}$

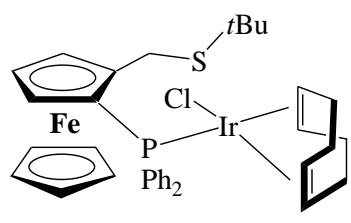

92

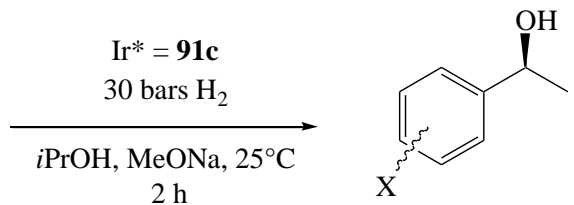

$73 \%$ e.e., $\mathrm{X}=p$-Me $\quad 99 \%$ e.e., $\mathrm{X}=p$-F

$76 \%$ e.e., $\mathrm{X}=p$-Cl $\quad\left(\mathrm{Ir}^{*}=\mathbf{9 1 b}, 91 \mathrm{c}, 10^{\circ} \mathrm{C}\right)$ :

$75 \%$ e.e., $\mathrm{X}=p$-F

\section{Scheme 56}

\section{Mechanistic considerations}

In many respects, one can imagine that the reductive transformation of ketones examined in this review follow the same mechanistic pathways as with other metals such as rhodium, ruthenium, iron, etc. The purpose of this section is not to review the mechanistic understanding of ketone hydrogenation in general. We wish, however, to highlight the mechanistic studies that have appeared in the literature with specific reference to the use of iridium.

\subsection{Hydrosilylation}

No mechanistic considerations making specific reference to the use of Ir in hydrosilylation appear to be available, paralleling the less frequent use of this metal for the catalytic tests. An early study on the use of $\left[\operatorname{Ir}(\mathrm{COE})_{2} \mathrm{Cl}\right]_{2} / \mathrm{PPh}_{3}$ as a precatalyst for the hydrosilylation of cyclohexanone by $\mathrm{Et}_{3} \mathrm{SiH}$ has shown that the best activity is obtained with a $\mathrm{P} / \mathrm{Ir}$ ratio of 1:1, whereas the catalyst becomes inactive when using a 2:1 ratio. This result has been attributed to the inertness of the $\left[\operatorname{IrHCl}\left(\mathrm{SiEt}_{3}\right)\left(\mathrm{PPh}_{3}\right)_{2}\right]$ adduct [12].

One interesting aspect is the reversal of enantioselectivity on going from $\mathrm{Rh}$ to $\mathrm{Ir}$, observed experimentally in several cases $[13,16,14,15]$. Moberg has observed an increase of enantioselectivity, the extent of which depends on the nature of the anion, upon the addition of silver salts to the $[\mathrm{MCl}(\mathrm{COD})]_{2} / \mathrm{L}^{*}$ precatalyst $(\mathrm{M}=\mathrm{Rh}, \mathrm{Ir})$ (Scheme 7). The cause of this 
phenomenon has been attributed to a secondary interaction, established by an $\mathrm{OH}$ function in the ligand. The Ir complex 93 (Scheme 57) was prepared and evidence for the presence of the secondary interaction was obtained by NMR. In further support of this hypothesis, a similar e.e. enhancement was not observed when using related ligands devoid of the $\mathrm{OH}$ function, e.g. 94. However, whether this interaction may also be associated to the reversal of absolute configuration is not clear.

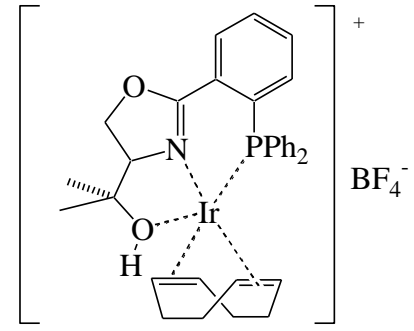

93

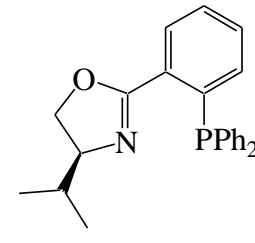

94

Scheme 57

\subsection{Transfer hydrogenation and hydrogenation}

These two transformations are treated together because catalysts that are active in one type of transformation are often (but not always) also active in the other one and the two mechanistic pathways may be closely related, sharing the path that leads to the transfer of two $\mathrm{H}$ atoms from a hydridic intermediate to the ketone substrate. The hydride intermediate may then be regenerated either by $\mathrm{H}_{2}$ addition or by the reverse of the hydrogen transfer process (from dihydrogen sources such as isopropanol or formic acid). As amply shown in the preceding sections, the most typical pre-catalysts are well-defined $\left[\operatorname{IrCl}\left(\mathrm{LL}^{\prime}\right)\right]_{2},\left[\operatorname{Ir}(\mathrm{COD})\left(\mathrm{LL}^{\prime}\right)\right]^{+}$ complexes or $1: 1[\mathrm{IrCl}(\mathrm{COD})]_{2} / \mathrm{LL}$ ' mixtures (LL' being chelating agents with a variety of different donor functions), although other type of complexes have been used as well, particularly those of type $\left[\mathrm{Cp}^{*} \operatorname{Ir}\left(\mathrm{LL}^{\prime}\right) \mathrm{Cl}\right]^{+}$.

\subsubsection{Survey of the proposed mechanisms}

All mechanistic possibilities are summarized in Scheme 58 in their simplest possible representation and consist of the "Noyori-Morris" or "outer sphere" mechanism (A) [85], two "inner-sphere" hydride mechanisms involving ketone coordination, insertion into the metalhydride bond, and product elimination (distinguished as a "monohydride" (B) and a "dihydride" 
(C) version [86]), and an "inner-sphere" direct transfer from the reducing agent to the coordinated substrate (D, a metal-templated, Meerwein-Ponndorf-Verley-type concerted mechanism which only applies to the TH process) [9]. The D cycle is generally considered less likely than the hydride mechanisms for transition metal-catalyzed TH processes [86], but certain experimental evidence, as will be shown below, seems most consistent with this mechanism for specific systems.
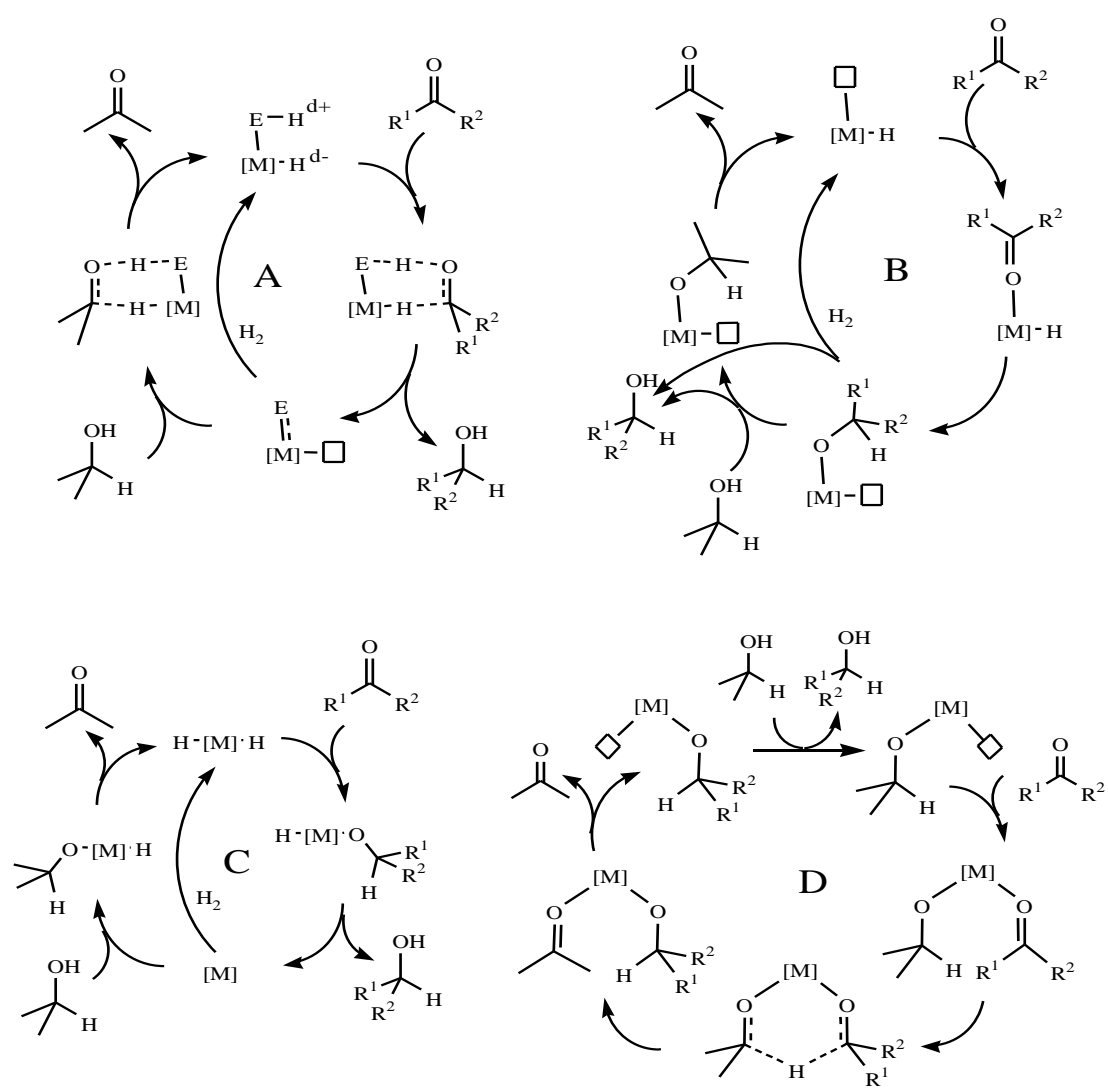

Scheme 58. Mechanistic pathways for hydrogenation and transfer hydrogenation of ketones

Cycle A can be subdivided into two versions, depending on whether the $\mathrm{H}^{+}$and $\mathrm{H}^{-}$ components are transferred to the $\mathrm{C}=\mathrm{O}$ substrate concertedly or stepwise (only the concerted version is shown in Scheme 58). Several other variants are possible for each mechanism, depending on whether the Ir center has the oxidation state I or III, on the state of protonation (many systems need a strong base to be activated), on the $\mathrm{H}_{2}$ activation mode (homolytic or heterolytic) for the hydrogenation process, and so forth. Note that the key hydride intermediate for cycles A-C (shown at the top of each cycle) can always be regenerated either by $\mathrm{H}_{2}$ or by a dihydrogen source (exemplified by isopropanol in Scheme 58). Therefore, these mechanistic possibilities apply to both hydrogenation and transfer hydrogenation. The metal center formally 
changes its oxidation state in cycle $\mathrm{C}$ while it does not need to in cycles $\mathrm{A}$ and $\mathrm{B}$. However, it may do so, limited to the hydrogenation cycles, if $\mathrm{H}_{2}$ is activated homolytically.

One important feature distinguishes cycles A, B and D on one side and C on the other, limited to transfer hydrogenation. For A, B (both "monohydride" mechanisms) and D, the "hydridic" $\mathrm{H}$ atom in the reductant (e.g. the $\alpha-\mathrm{H}$ atom of isopropanol) selectively becomes the "hydridic" $(\alpha-H)$ atom in the product, whereas in cycle $\mathrm{C}$ this atom is distributed with equal probability to the $\mathrm{CH}$ and $\mathrm{OH}$ positions. Thus, useful information can be obtained by use of selectively deuterated reductants such as $d_{1}$-cyclohexanol or racemization studies of an optically active $\alpha$-deuterated alcohol such as $d_{1}$-phenylethanol (see scheme 59 ), allowing to exclude at least one mechanistic possibility. However, cycles A, B and D cannot be told apart by this experiment.

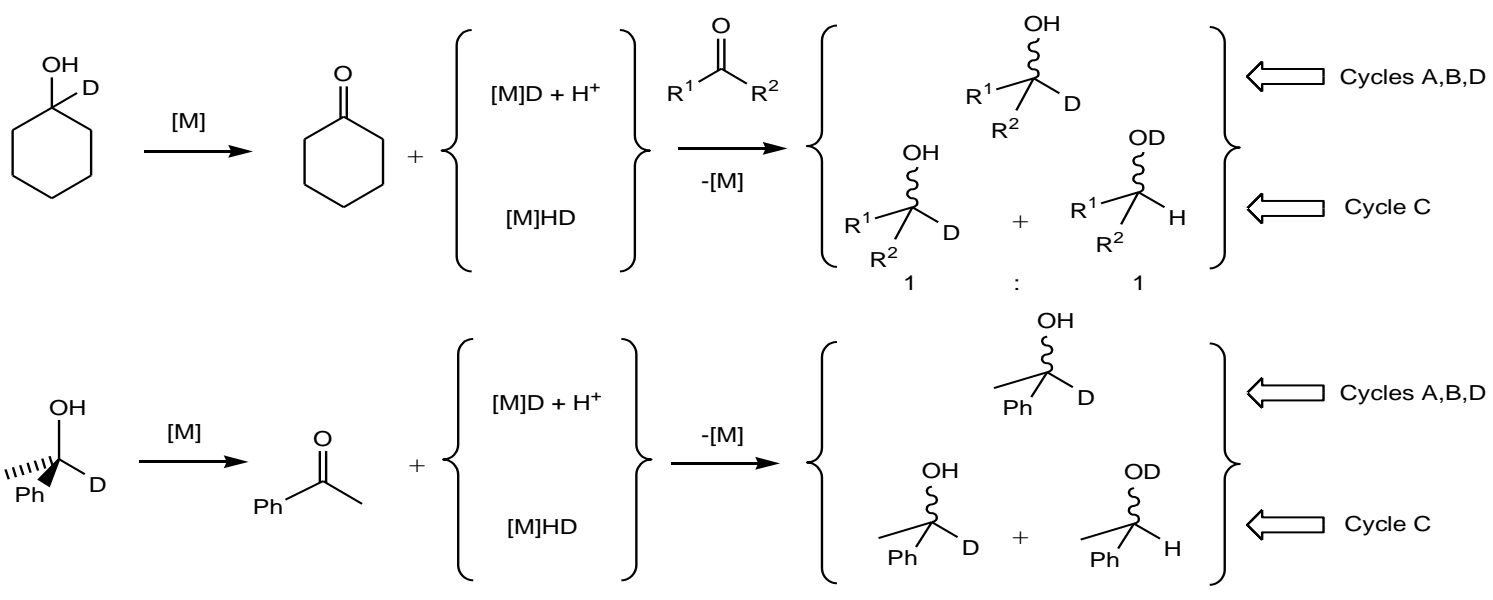

Scheme 59

Isotope labelling experiments of these types have been carried out in transfer hydrogenation mechanistic studies, including some involving Ir compounds. Bäckvall et al. [87] reported that catalysts $\mathbf{9 5 - 9 9}$ (Scheme 60) give rise to a high deuterium incorporation into the product $\alpha-C$ position, the slight $\mathrm{D}$ loss being attributed to ortho-metallation processes that are more pronounced for the phosphine-containing catalysts (98 and 99). Crabtree et al. found analogous results for the transfer hydrogenation of acetophenone by $d_{1}$-cyclohexanol catalyzed by the bis(NHC) Ir III complex 100 [88]. 


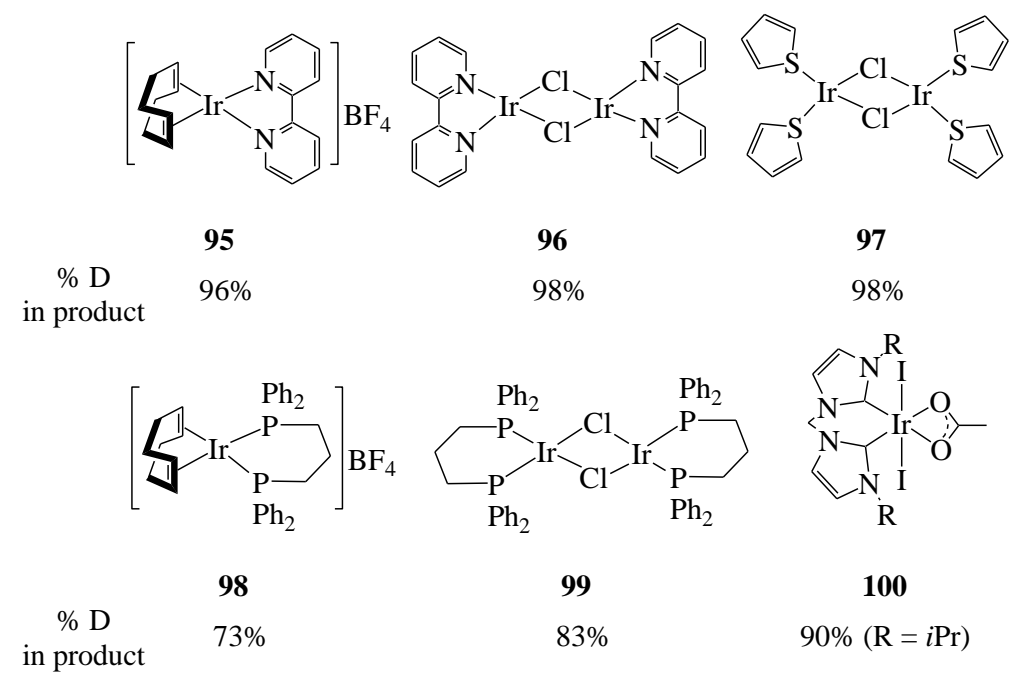

Scheme 60. Use of iridium catalysts for mechanistic studies with $\alpha$-deuterated reductant

Another key difference between the four mechanistic possibilities of Scheme 58, limited to the hydrogen transfer process, concerns the effect of the $\mathrm{H}$ donor nature on the enantioselectivity. In cycles A, B and C, the chiral induction step ( $\mathrm{H}$ transfer to the substrate) occurs independently from the intervention of the hydrogen donor molecule in the hydride catalyst regeneration sequence. Therefore, the enantioselectivity is expected to be independent from the nature of the hydrogen donor [89]. In cycle D, on the other hand, the hydrogen donor molecule transfers one $\mathrm{H}$ atom directly to the substrate. Therefore, the observation of a donordependent enantiomeric excess should be considered as indication of the metal-templated mechanism. Most studies, however, have limited themselves to the use of a single donor molecule (most typically isopropanol) and have not addressed this point. An exception is a study published by van Leeuwen et al. using $[\operatorname{Ir}(\mathrm{COD}) \mathrm{Cl}]_{2}$ in the presence of the aminosulf(ox)ides 40-54 [50], where a pronounced donor-dependence (isopropanol vs. formic acid) of the enantioselectivity was observed. For instance, reduction of acetophenone gave the alcohol product with an e.e. of $23 \%(\mathrm{~S})$ when using formic acid/NEt 3 and $24 \%(\mathrm{R})$ when using isopropanol in the presence of ligand 49 , or $58 \%(\mathrm{~S})$ and $80 \%(\mathrm{R})$, respectively, in the presence of ligand 52. Thus, the authors conclude that a metal-templated direct transfer might be possible for this system. It is also possible that a different mechanism is operating with each of the two different $\mathrm{H}$ transfer agents. However, one must be cautious because an important effect on the enantioselectivity may also be caused by the different solvent nature (neat $\mathrm{HCOOH} / \mathrm{NEt}_{3}$ azeotrope and $i \mathrm{PrOH}$, respectively).

The highest activity in ketone reduction processes, especially the transfer hydrogenation (TH) type, is arguably shown by catalysts featuring the Ru-NH linkage [90] with TOF up to 
$10^{6} \mathrm{~h}^{-1}$ at $50 \%$ conversion [91]. The utility of complexes having the Ir-NH functionality, or other Ir-EH functionalities with mobile protons (e.g. Ir-OH with aminoalcohol ligands), has also been demonstrated and these systems are therefore proposed to operate through cycle A $[29,32,40,54,92]$. In a recent study of the ATH by formate catalyzed by $\mathrm{Rh}^{\mathrm{III}}$ and $\mathrm{Ir}^{\mathrm{III}}$ complexes in water, the activity was found to be highest at intermediate $\mathrm{pH}$ (ca. 7 for both metals) [43]. This catalyst was proposed to operate by the outer-sphere cycle A with the highest activity resulting from the neutral form $\mathbf{A}$ (Scheme $61, \mathbf{M}=\mathrm{Rh}$ or Ir; cycle I), obtained in situ from the chloride precursor and formate. At low $\mathrm{pH}$ a less active cationic complex $\mathbf{B}$ would operate though an alternative cycle II (possibly through decoordination of the NHTs function in order to explain the lower enantioselectivities), whereas an inactive hydroxide complex $\mathbf{C}$ would form at high $\mathrm{pH}$ (the enantioselectivity is not affected at high $\mathrm{pH}$ ).

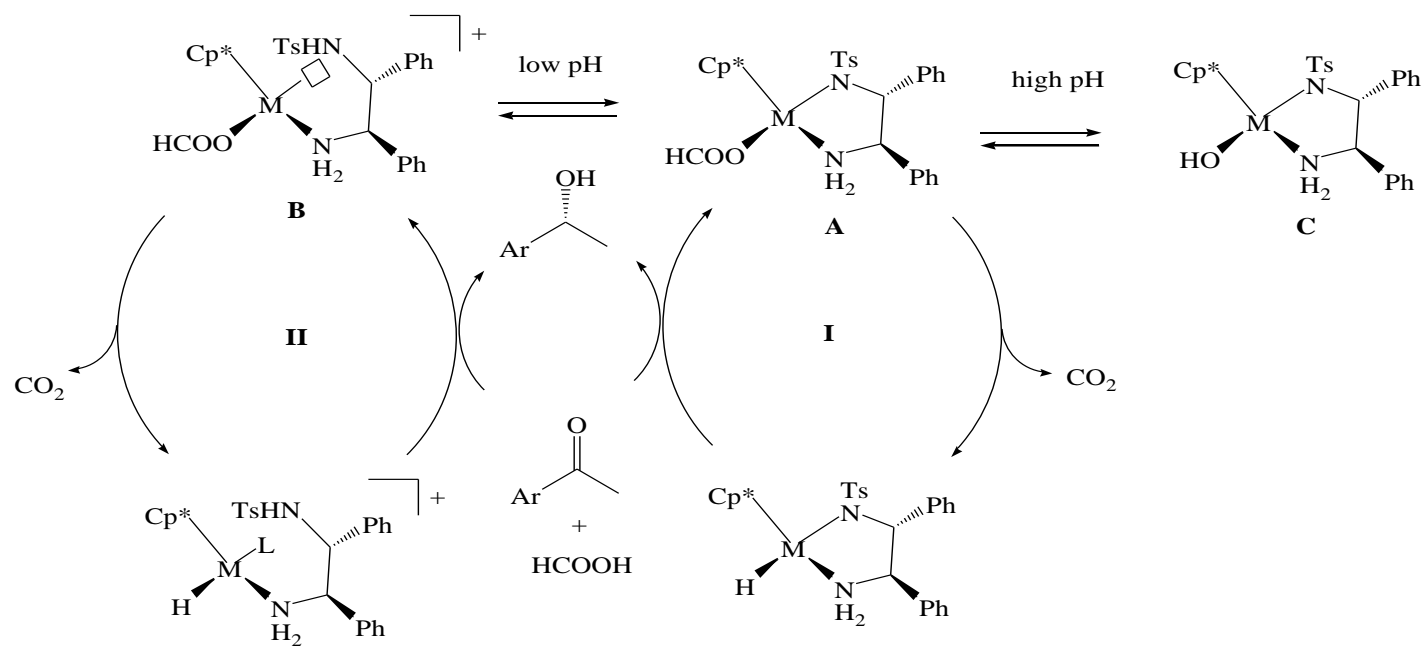

Scheme 61

The related catalyst 36a (Scheme 28) was also shown to provide the highest activity in the presence of mild bases, whereas stronger ones deactivate it [45]. This system gives the same activity as the mononuclear chloride analogue, suggesting that the active form is a mononuclear solvated species D (Scheme 62), which seems consistent with the observed negative influence of excess chloride ions. This species would then be converted into the active hydride complex $\mathbf{E}$ in the presence of base. Both cycles A and B have been considered as possibilities, although it was argued that the lower activity of the Me-substituted prolinate complex (36b) militates in favour of cycle A. The intermediate of cycle B would also require partial decoordination of the prolinate ligand or $\mathrm{Cp}^{*}$ slippage in order to avoid a 20-electron configuration. 


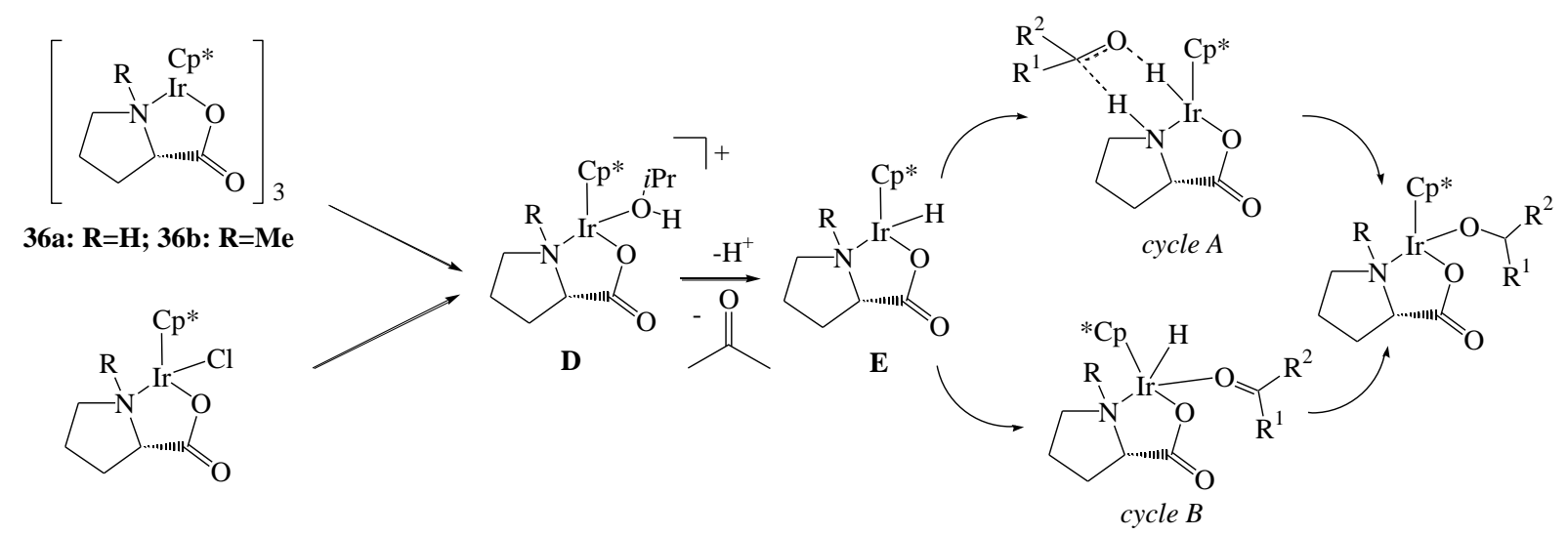

Scheme 62

The hydrogenation and transfer hydrogenation processes are also catalyzed, however, by complexes with "non N-H" ligands, such as those of Scheme 60. The highest activity for Ir catalysts has in fact been obtained with ligands that do not contain mobile protons on the donor functions. ${ }^{65}$ Thus, cycles B or D seem more appropriate for these systems if the deuterium labelling experiments suggest a "monohydride" route. Cycle B has been proposed, for instance, by Crabtree et al. [88] for system 100 (Scheme 60) and by Lemaire et al. for system $[\operatorname{Ir}(\mathrm{COD}) \mathrm{Cl}]_{2} / \mathbf{1 6}$ (Scheme 17) [30]. Many of these mechanistic propositions, however, do not address the metal oxidation state and the precise coordination geometry of the operational catalyst. Other authors, on the other hand, have proposed the metal-templated cycle D. In the proposition by Zassinovich and Mestroni [25], the key system obtained from $\left[\operatorname{Ir}(\mathrm{COD}) \mathrm{L}_{2}\right]^{+}$ would be the 5-coordinate $\operatorname{Ir}^{\mathrm{I}}$ species $\mathbf{F}$ (see scheme 63), a proposition later reinforced by the observed increased activity in the presence of the iodide ion [26] (which would occupy the X position).

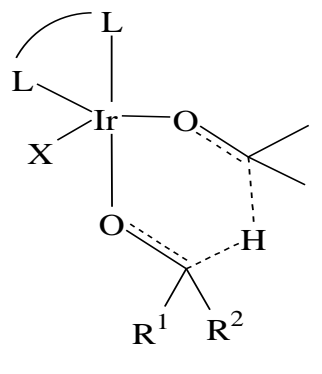

$\mathbf{F}, \mathrm{X}=i \mathrm{PrOH}, \mathrm{OH}^{-}$

\section{Scheme 63}

Dahlenburg and Götz have reported H/D exchange processes involving the Ir catalysts 86 and 101 (Schemes 54 and 64) [82]. Hydrogenation of acetophenone or benzophenone with 
$\mathrm{H}_{2}$ in $\mathrm{CH}_{3} \mathrm{OD}$ gave invariably mixtures of $\mathrm{R}^{1} \mathrm{R}^{2} \mathrm{CHOD}$ and $\mathrm{R}^{1} \mathrm{R}^{2} \mathrm{CDOD}$ in approximately $1: 1$ ratio, accompanied by the observed evolution of HD and the increase in the amount of nondeuterated methanol. However, no such uptake of $\mathrm{D}^{+}$as $\mathrm{D}^{-}$into the carbinol products was observed when using 102 (Scheme 64), which does not contain a mobile proton on the nitrogen donor function. The Ir complexes containing NH donor groups, but not $\mathbf{1 0 2}$ were also shown to catalyze H/D exchange with formation of $\mathrm{HD}$ from $\mathrm{H}_{2} / \mathrm{CH}_{3} \mathrm{OD}$ mixtures, as well as from $\mathrm{H}_{2} / \mathrm{D}_{2}$ mixures in $\mathrm{CH}_{3} \mathrm{CN}$, in the absence of ketone substrates. Long-lived $\operatorname{Ir}\left(\mathrm{H}_{2}\right)$ complexes could not be detected, but this observation indicated the ability of $\mathrm{Ir}^{+}$to bind $\mathrm{H}_{2}$, to activate it heterolytically, and to exchange the $\mathrm{H}_{2}$ "proton" with the $\mathrm{NH}$ function, the absence of which does not allow any exchange.

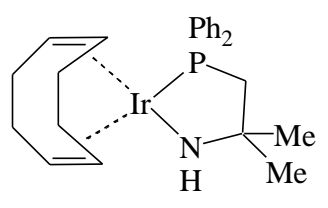

101

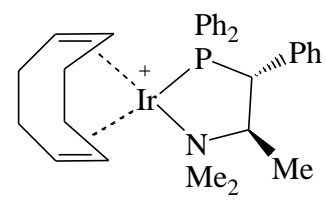

$102(R, R)$

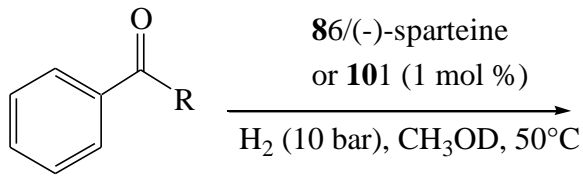

$\mathrm{R}=\mathrm{Me}, \mathrm{Ph}$<smiles>[R]C(=O)c1ccccc1</smiles>

$\mathrm{R}=\mathrm{Me}, \mathrm{Ph}$

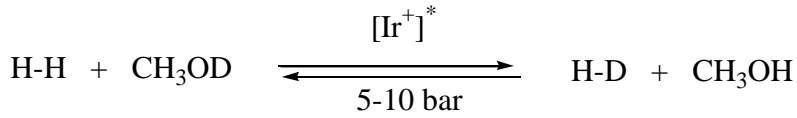

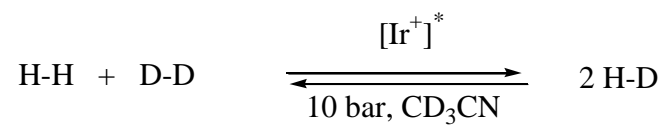

$$
\begin{aligned}
& \text { * Any NH-containing } \mathrm{Ir}^{+} \text {complex }
\end{aligned}
$$

$(56 \pm 5 \%) \quad(44 \pm 5 \%)$

$\left(+\mathrm{HD}+\mathrm{CH}_{3} \mathrm{OH}\right)$

\section{Scheme 64}

In the same contribution, it was also established that $\mathrm{H}_{2}$ oxidatively adds to neutral amido complexes such as $\mathbf{1 0 1}$ and also to the corresponding protonated cationic amino complexes (e.g. $\mathbf{1 0 1} \mathrm{H}^{+}$in Scheme 65), to yield dihydrido IrII derivatives $\left(\mathbf{1 0 3}\right.$ and $\mathbf{1 0 3} \mathrm{H}^{+}$, respectively). Whereas the $\operatorname{Ir}^{\mathrm{I}}$ complexes do no undergo rapid acid/base equilibration, the $\mathrm{Ir}^{\mathrm{III}}$ complexes do, this being attributed to the better availability of the $\mathrm{N}$ lone pair in the 
electronically saturated $\mathrm{Ir}^{\mathrm{III}}$ species. These $\mathrm{Ir}^{\mathrm{III}}$ products are also capable to undergo H/D exchange between the coordinated $\mathrm{NH}$ proton(deuteron) and $\mathrm{H}_{2}$. At longer reaction times, however, COD is lost as hydrogenation product, yielding solvated Ir ${ }^{\mathrm{III}}$ hydrides.

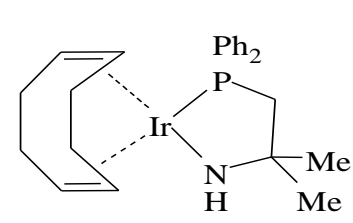

101

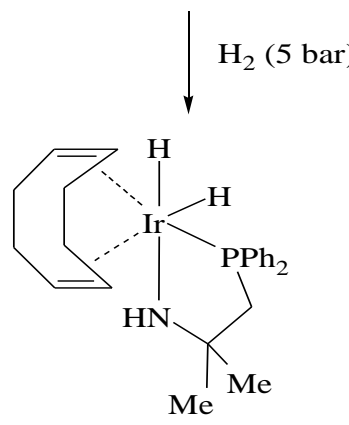

103

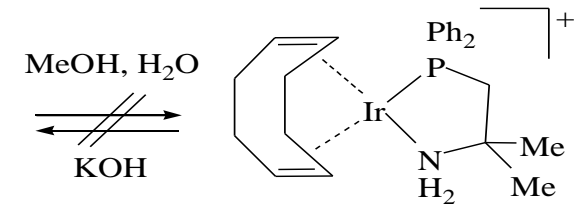

$101 \mathrm{H}^{+}$

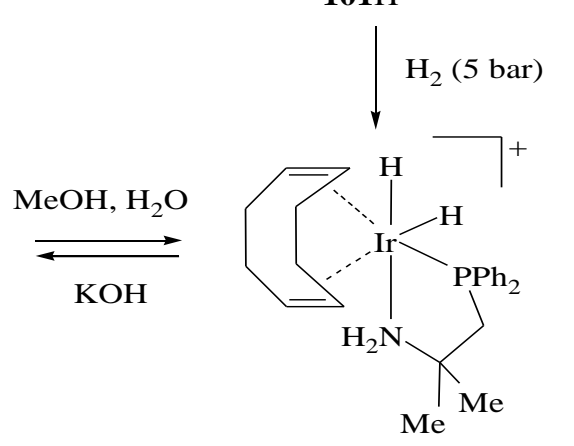

$103 \mathrm{H}^{+}$

\section{Scheme 65}

On the basis of the above observations, Dahlenburg and Götz proposed a mechanism for the hydrogenation catalytic cycle which involves ketone coordination and insertion (type B, Scheme 58) into an Ir ${ }^{\mathrm{III}}-\mathrm{H}$ bond of a neutral $\mathrm{Ir}^{\mathrm{III}}$ amido species in which the positions formerly occupied by the COD ligands are saturated by solvent molecules. However, the reactivation by $\mathrm{H}_{2}$ would not occur by $\mathrm{H}_{2}$ addition to the neutral alkoxide intermediate but rather to a cationic species obtained after protonolysis of the Ir-alkoxide function, liberating the product, as shown in Scheme 66 [82]. Complex $\mathbf{G}$ in this scheme would be common to the catalytic ketone hydrogenation and H/D exchange cycles. This mechanism, of course, cannot be valid when using compound 102 (Scheme 64), which was also shown within the same contribution to be an active catalyst [82]. 

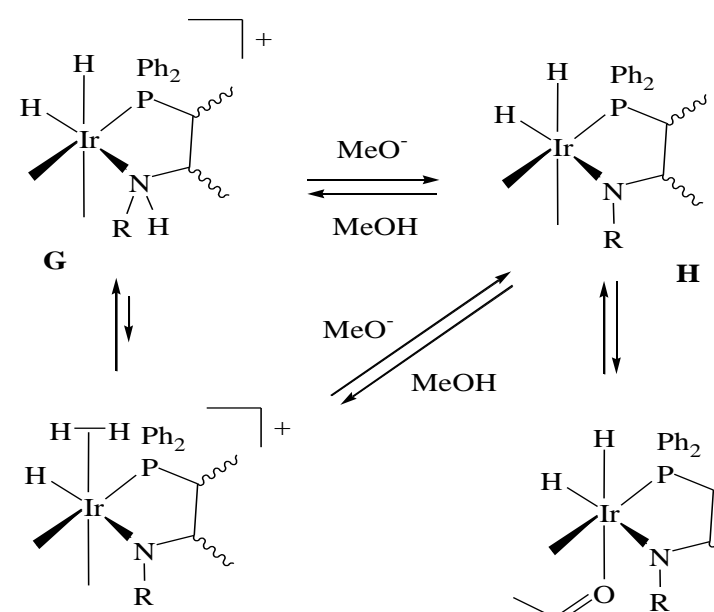

$\mathbf{L}$

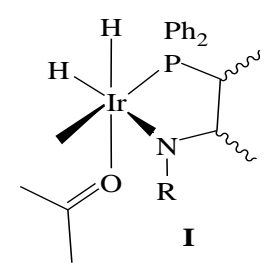

$\mathrm{H}_{2} \uparrow$

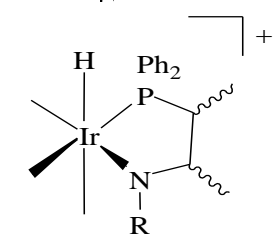

$\mathbf{K}$
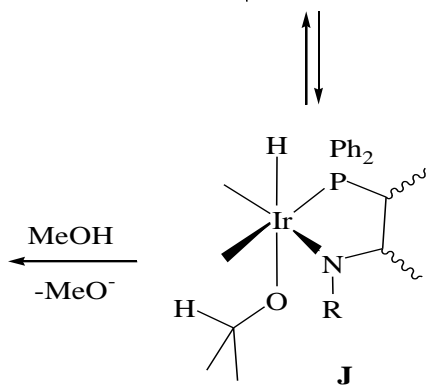

Scheme 66

\subsubsection{Open questions}

As is evident from the above survey, the variety of catalytic systems and conditions and the paucity of mechanistic investigations do not provide a clear view of the structure/activity and structure/mechanism relationship. Several points deserve consideration, only few of them being explicitly addressed in previously published studies.

\section{(a) $\operatorname{Ir}(I)$ or $\operatorname{Ir}(I I I)$ ?}

For hydrogenation reactions, it is usually assumed that the cycle operates through $\mathrm{Ir}^{\mathrm{III}}$ species because of the well known propensity of iridium to undergo $\mathrm{H}_{2}$ oxidative addition reactions. Studies by Crabtree et al. have shown that $\left[\operatorname{Ir}(\mathrm{COD}) \mathrm{L}_{2}\right]^{+}$complexes react with hydrogen to yield $\left[\mathrm{IrH}_{2} \mathrm{~L}_{2} \mathrm{~S}_{2}\right]^{+}$derivatives ( $\mathrm{S}=$ solvent), which were proven intermediate of the olefin hydrogenation catalytic cycle. ${ }^{93}$ The involvement of the same type of intermediates in the hydrogenation or transfer hydrogenation of polar substrates such as ketones, however, is not clear, especially for processes taking place through the "outer-sphere" pathway. The precatalysts used in $\mathrm{TH}$ are often $\operatorname{Ir}^{\mathrm{I}}$ complexes which, in the presence of bases and hydrogen donors, should give rise to $\operatorname{Ir}^{\mathrm{I}}$ hydride species as exemplified in Scheme 67 for the specific 
examples of a neutral chloro complex and for a cationic (COD) $\operatorname{IrL}_{2}{ }^{+}$complex. The $\left[\operatorname{IrCl}\left(\mathrm{LL}^{\prime}\right)\right]_{2}$ system can convert to an isopropoxide complex $\mathbf{M}$ to yield the hydride $\mathbf{N}$ through elimination of acetone (or through an equivalent formate intermediate and elimination of $\mathrm{CO}_{2}$ if $\mathrm{HCOOH}$ is used as transfer agent). The $\left[\operatorname{Ir}(\mathrm{COD})\left(\mathrm{LL}^{\prime}\right)\right]^{+}$system, on the other hand, can analogously lead to the 16-electron or 18-electron hydride $\mathbf{P}$ via the isopropoxide $\mathbf{O}$. The question is then whether this system can catalyse itself transfer hydrogenation, or whether it does so only after elimination of the COD ligand as cyclooctene or cyclooctane by transfer hydrogenation (this point will be discussed again later). At any rate, the system would remain in the oxidation state I. In order to generate $\mathrm{Ir}^{\mathrm{III}}$, oxidative addition of alcohol to yield a hydrido alkoxo derivative is necessary, but this process has not so far been documented to the best of our knowledge for an $\mathrm{Ir}^{\mathrm{I}}$ system. On the other hand, use of $\mathrm{Ir}^{\mathrm{III}}$ pre-catalysts does not guarantee that this oxidation state is retained in the active form, because basic conditions may facilitate reduction (Scheme 68). These considerations also apply to hydrogenation catalysts, when these operate under strongly basic conditions, especially in alcohol solvents.

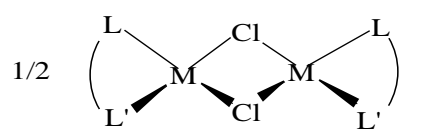

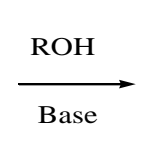<smiles>CC(C)O[Al]1[I-][I-]1</smiles>

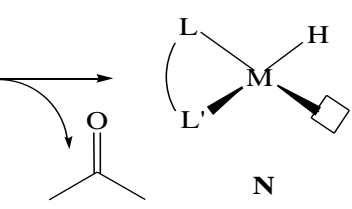

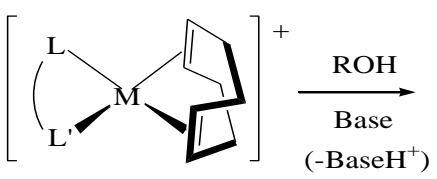

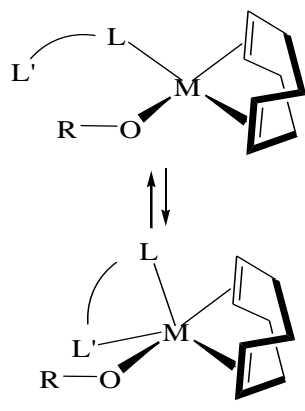

O

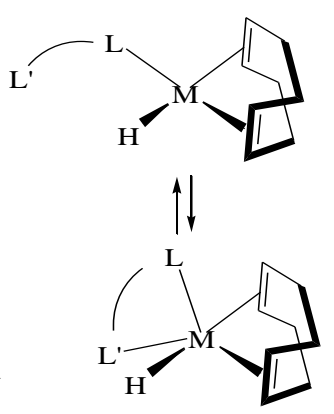

P

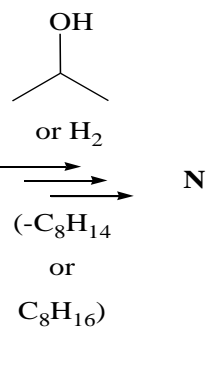

Scheme 67

$$
\begin{gathered}
\mathrm{Ir}^{\mathrm{III}}+\mathrm{AH}_{2}+2 \mathrm{~B} \longrightarrow \mathrm{Ir}^{\mathrm{I}}+2 \mathrm{BH}^{+}+\mathrm{A} \\
\left(\mathrm{A}=\text { hydrogen acceptor, e.g. acetone or } \mathrm{CO}_{2}\right) \\
\mathrm{Ir}^{\mathrm{III}}-\mathrm{H}^{+}+\mathrm{B} \longrightarrow \mathrm{Ir}^{\mathrm{I}}+\mathrm{BH}^{+}
\end{gathered}
$$

Scheme 68 
The direct comparison between $\operatorname{Ir}^{\mathrm{I}}$ and $\mathrm{Ir}^{\mathrm{III}}$ precursors with the same ligand system is rare. Studies of a series of different catalytic precursors containing the PYBOX ligand show that higher activities and enantioselectivities are obtained when using the $\mathrm{Ir}^{\mathrm{III}}$ precursors. For instance, complexes $\left[\operatorname{IrClH}\left(\eta^{2}-\mathrm{C}_{2} \mathrm{H}_{4}\right)(i \mathrm{Pr}-\mathrm{PYBOX})\right]\left[\mathrm{PF}_{6}\right]$ and $\left[\mathrm{IrCl}_{3}(i \mathrm{Pr}-\mathrm{PYBOX})\right]$ gave reduction of acetophenone by isopropanol with conversions (and e.e. for the alcohol product) of $96[67(\mathrm{R}) \%]$ and $96 \%[56(\mathrm{R}) \%]$ in two hours, whereas complex $\left[\operatorname{Ir}\left(\eta^{2}-\mathrm{C}_{2} \mathrm{H}_{4}\right)_{2}(i \operatorname{Pr}-\right.$ $\mathrm{PYBOX})]\left[\mathrm{PF}_{6}\right]$ gave $66 \%$ conversion with e.e. of $50(\mathrm{R}) \%$ under the same conditions [63]. The in situ $\left[\mathrm{IrCl}(\mathrm{COE})_{2}\right]_{2} / \mathrm{PYBOX}$ catalyst also performs less efficiently. All these systems, however, require activation to generate the active form. The best results were obtained by addition of the iridium catalyst precursor to a solution of ketone in $i \mathrm{PrOH}$, stirring the resulting mixture at $82{ }^{\circ} \mathrm{C}$ for $15 \mathrm{~min}$, and final addition of $\mathrm{KOH}$. Unfortunately, no spectroscopic studies are reported on the product of this catalyst activation step. Other attempts at identifying the nature of the iridium complex formed under catalytic conditions failed $[54,88]$, indicating that these species are quite delicate. Crabtree et al. have investigated the deactivation of the transfer hydrogenation catalyst 100 (Scheme $60, \mathrm{R}=i \mathrm{Pr}$ ) and found that the catalyst is stable in the absence of base or in the presence of base and substrate, but decomposes in the presence of the base alone. This indicates that gradual decomposition of the active catalyst occurs under strongly basic conditions unless protected by the substrate [88]. The precise nature of the decomposition products, however, could not be elucidated.

\section{(b) Denticity/activity relationship}

Most catalysts use bidentate LL' $\left(\mathrm{L}^{\prime}=\right.$ or $\left.\neq \mathrm{L}\right)$ ligands. Others, however, use tridentate ligands such as PYBOX and even tetradentate ones such as the P,N,N,P ligands 62 and 63 or $\mathrm{N}_{4}$ ligands 64 and 65 (Schemes 37 and 38), several of them being devoid of donor function with mobile protons. Thus, the question is whether the ligand must decoordinate to generate a free coordination site (such as in $\mathbf{N}$ in Scheme 67, or whether the $\operatorname{Ir}^{\mathrm{I}}$ system is capable to operate through 5-coordinate intermediates, or finally whether the active form is an $\mathrm{Ir}^{\mathrm{III}}$ complex with an octahedral coordination environment. The systems based on PYBOX appear rather slow, since high conversions within $1-2 \mathrm{~h}$ with $0.2 \%$ catalyst required the use of high temperatures $\left(82^{\circ} \mathrm{C}\right)[63]$, while other systems with bidentate ligands give similar rates at room temperature. The P,N,N,P ligand 62, on the other hand, gives nearly quantitative conversion in $2 \mathrm{~h}$ at room temperature for acetophenone $(0.5 \%$ catalyst $)$. The nature of the precatalyst was shown to be $[\operatorname{IrCl}(41)]$ by isolation and spectroscopic characterization [55]. 


\section{(c) Solvent effects on activity and on enantioselectivity}

For TH, it seems that isopropanol is the reagent/solvent of choice and the need of a large excess in order to displace equilibrium for the nearly thermoneutral reaction limits the investigation of solvent effects. For hydrogenation reactions, the solvent nature appears to have a dramatic effect. The Ir-catalyzed hydrogenation of the $\alpha, \beta$-unsaturated ketone trans$\mathrm{PhCH}=\mathrm{CHCOMe}[94]$ gives predominantly the saturated ketone $(\mathrm{C}=\mathrm{C}$ hydrogenation product $)$ with low activities in $\mathrm{CH}_{3} \mathrm{COOH}$ and $1,2-\mathrm{C}_{2} \mathrm{H}_{4} \mathrm{Cl}_{2}$, whereas the unsaturated alcohol $(\mathrm{C}=\mathrm{O}$ hydrogenation product) is obtained in alcohols, THF, dioxane, DMF and toluene. Thus, the solvent seems to play a determining role in the chemoselectivity toward the reduction of $\mathrm{C}=\mathrm{C}$ vs. $\mathrm{C}=\mathrm{O}$ bonds. Low activities in $\mathrm{C}=\mathrm{O}$ hydrogenation are typically found in chlorinated solvents and attributed to the release of $\mathrm{Cl}^{-}$under the reaction conditions, blocking the catalytic activity by irreversibly coordinating to the metal center [73]. High activities in the reduction of polar unsaturations are generally observed in polar coordinating solvents. The relative performance of THF and water for the catalysts with the chiral diamines 77 (Scheme 47) was shown to depend on the nature of the chiral ligand and substrate [74]. Alcohols always appear as suitable solvents for hydrogenation activity, though not always leading to the highest enantioselectivities. The relative activity in the alcohol solvents is often in favour of $i \mathrm{PrOH}$ (for instance for catalysts 91 [84] and $\mathrm{IrH}_{3}\left(\mathrm{P}\left[\mathrm{CH}_{2} \mathrm{CH}(\mathrm{Me}) \mathrm{Et}\right] \mathrm{Ph}_{2}\right)_{3}$ [94]) hinting at the possibility of a transfer hydrogenation mechanism, but exceptions have also been recorded (for instance $\mathrm{MeOH}>\mathrm{EtOH}, i \mathrm{PrOH}$ for catalyst 90b) [95] and the systems are also often active in solvents incapable of acting as hydrogen donors [84,94], demonstrating that $\mathrm{H}_{2}$ is the reducing agent, at least in the latter solvents. In alcohol solvents, the coexistence of hydrogenation and transfer hydrogenation is possible, since the active catalyst can be regenerated by both the alcohol and $\mathrm{H}_{2}$ (see Scheme 58). An intriguing observation has been obtained in our group for the hydrogenation with catalysts 91: while good activity is observed in $\mathrm{MeOH}, \mathrm{EtOH}$ and $i \mathrm{PrOH}$, the catalyst does not work in $t \mathrm{BuOH}$. Since this alcohol is devoid of $\alpha-\mathrm{H}$ atoms, the occurrence of a TH mechanism would seem indicated. However, this catalyst also works well in toluene and $\mathrm{MeCN}$, demonstrating the viability of a hydrogenation mechanism [84]. How the presence of $t \mathrm{BuOH}$ blocks the hydrogenation pathway, contrary to the lower alcohols and the other non protic solvents, is not yet understood.

\section{(d) Is diene removal in "Ir(diene)"-type pre-catalysts necessary?}

An interesting and much debated question is whether the diene ligand in dienecontaining pre-catalysts remains in the coordination sphere of the active catalyst or whether it 
is eliminated as a hydrogenated product. This point has already been outlined in Scheme 67 for the typical case of COD-containing systems. For hydrogenation processes with $\mathrm{H}_{2}$, there is little doubt that the catalytic species no longer contains the COD ligand. Indeed, evidence for the generation of COD hydrogenation products under ketone hydrogenation catalytic conditions has been presented [82]. For TH catalysis, an early study by Bakos et al. [23] shows that $\left[\operatorname{Ir}(\mathrm{COE})_{2} \mathrm{Cl}\right]_{2}$ in combination with the diphosphinite ligand BDPOP (Scheme 11) in isopropanol led to quantitative loss of free $\mathrm{COE}$ within $5 \mathrm{~min}$ at room temperature, whether $\mathrm{NaOMe}$ was present or not. The resulting catalyst was able to isomerize 1,5-COD to 1,3-COD and to hydrogenate both dienes to $\mathrm{COE}$, but not further to cyclooctane. In contrast, the related $[\operatorname{Ir}(1,5-\mathrm{COD}) \mathrm{Cl}]_{2}$ precatalyst needed $60 \mathrm{~min}$ for complete loss of the organic ligand, again selectively as COE. After $5 \mathrm{~min}$ at room temperature in the absence of base, the distribution of the free organic ligand was 40\% 1,5-COD, 40\% 1,3-COD and 20\% COE, but subsequent reflux for $30 \mathrm{~min}$ in the presence of base let to selective and quantitative hydrogenation to COE. It therefore appears that hydrogenation of COD to COE by hydrogen transfer from isopropanol is a facile process, at least when $\mathrm{L}_{2}$ is a diphosphinite ligand. Thus, the presence of an induction times, as expected if the activation follows the pathway of Scheme 67 leading from $\mathbf{P}$ to $\mathbf{N}$, may be difficult to detect. Activation times are well established when rhodium catalysts of this type are used for the hydrogenation of olefins [96].

Graziani et al. have reported the need to activate $\left[\operatorname{Ir}(\operatorname{diene}) \mathrm{L}_{2}\right]^{+}$precatalysts (diene $=$ norbornadiene, $\mathrm{COD} ; \mathrm{L}_{2}=$ diphosphine) by reflux in isopropanol for a certain time $\mathrm{T} 1$, followed by treatment with $\mathrm{KOH}$ for an additional time T2, in order to obtain best activities in ATH [21]. The solution colour changed from red to yellow during the initial time T1 and the yellow product was isolated but could not be characterized. Based on NMR $\left({ }^{1} \mathrm{H}\right.$ and $\left.{ }^{31} \mathrm{P}\right)$ and IR evidence, this seemed to correspond to a fluxional complex containing terminal and bridging hydrides, similar to dinuclear $\operatorname{Ir}(\mathrm{III})$ complexes reported by Crabtree, $\left[\operatorname{Ir}_{2}\left(\mu-\mathrm{H}_{3} \mathrm{H}_{2} \mathrm{~L}_{4}\right]^{+}\right.$, which were inactive as olefin hydrogenation catalysts [97] but which could reconverted into a catalytically active form upon treatment with $\mathrm{KOH}$ [21]. This evidence, therefore, seems to indicate that COD elimination is necessary to improve catalytic activity. It does not, however, prove that the active catalyst contains $\mathrm{Ir}^{\mathrm{III}}$, because deprotonation by $\mathrm{KOH}$ would generate again an $\operatorname{Ir}^{\mathrm{I}}$ species. Under identical conditions, systems of type $\left[\operatorname{IrCl}\left(\mathrm{LL}^{\prime}\right)\right]_{2}$ have been shown to need shorter times that those of type $\left[\operatorname{Ir}(\mathrm{COD})\left(\mathrm{LL}^{\prime}\right)\right]^{+}$with the same bidentate ligand to yield comparable conversions, also hinting to the need to remove the COD ligand [87].

On the other hand, evidence that the diene ligand is retained in the active catalyst in transfer hydrogenation catalysis has been reported for related rhodium systems (for which no 
induction times could be detected) by the Lemaire group, as suggested by the different catalytic activity and enantioselectivity of $[\mathrm{RhCl}(\text { diene })]_{2} / 2 \mathrm{LL}$ ' and $\left[\mathrm{RhCl}(\text { olefin })_{2}\right]_{2} / 2 \mathrm{LL}$ ' with different dienes and olefins [98]. The observation by van Leeuwen et al. of the greater catalytic activity of $[\operatorname{Ir}(\mathrm{COD}) \mathrm{Cl}]_{2}$ relative to $\left[\mathrm{IrCl}(\mathrm{COE})_{2}\right]_{2}$ under identical conditions (ligand: 41a, Scheme 35; transfer agent: $\mathrm{HCOOH} / \mathrm{NEt}_{3}$ ) [50] seems to exclude the need of COD reduction for activation. Indeed, if COD hydrogenation were necessary to generate the active species, the activity of $[\operatorname{IrCl}(\mathrm{COD})]_{2}$ would be lower, not higher, than that of $\left[\mathrm{IrCl}(\mathrm{COE})_{2}\right]_{2}$.

\subsubsection{Computational studies}

Computational investigations of hydrogenation catalysis specifically using Ir systems are rare. Partly on the basis of the evidence presented in the previous section, computational studies were carried out on various possible pathways starting from intermediates of type $\mathbf{P}$ (Scheme 67), most of these involving only Rh systems. For the $\mathrm{RhH}\left(\mathrm{C}_{2} \mathrm{H}_{4}\right)_{2}\left(\mathrm{NH}_{3}\right)_{2}$ model system, the "inner-sphere" monohydride pathway (cycle B in Scheme 58) was found to be a viable pathway, with a smooth energy profile and relatively low activation barriers [99]. However, a later study showed that the "inner-sphere" concerted mechanism (cycle A in Scheme 58) has even lower activation barriers. This mechanism is also low-energy for the model complex $\mathrm{RhH}\left(\mathrm{C}_{2} \mathrm{H}_{4}\right)_{2}(\mathrm{MeHNCHRCHRNMeH})(\mathrm{R}=\mathrm{H}, \mathrm{Me}, \mathrm{Ph})$ [100]. The only computational study specifically addressing an Ir catalyst that has appeared to date, to the best of our knowledge, examines the model systems $\mathrm{IrH}(\mathrm{COD})\left(\mathrm{NH}_{2} \mathrm{CH}_{2} \mathrm{CH}_{2} \mathrm{X}\right)\left(\mathrm{X}=\mathrm{OH}, \mathrm{SCH}_{3}\right)$ [101]. In this study, the three cycles A, B and D of Scheme 58 are compared, the critical transition states being represented in Scheme 69. Although the barrier for cycle A leading from the hydride intermediate to the $\operatorname{Ir}(\mathrm{COD})\left(\mathrm{NHCH}_{2} \mathrm{CH}_{2} \mathrm{X}\right)+i \mathrm{PrOH}$ products is small and comparable to that found for the Ru model $\left(\mathrm{C}_{6} \mathrm{H}_{6}\right) \mathrm{RuH}\left(\mathrm{NH}_{2} \mathrm{CH}_{2} \mathrm{CH}_{2} \mathrm{O}\right)$, the system was found to be much more stabilized by isopropanol coordination with formation of $\operatorname{Ir}(\mathrm{O} i \operatorname{Pr})(\mathrm{COD})\left(\kappa^{1}: N-\right.$ $\mathrm{NH}_{2} \mathrm{CH}_{2} \mathrm{CH}_{2} \mathrm{X}$ ) ( $\mathbf{Q}$ in Scheme 69), relative to the $\mathrm{Ru}$ model. Thus, the H-bonded hydride complex - carbonyl substrate adduct leading to TS (cycle A) is located at 27.2 and $22.8 \mathrm{kcal} / \mathrm{mol}$ above $\mathbf{Q}$ for the Ir systems with $\mathrm{X}=\mathrm{OH}$ and SMe, respectively, $v s$. only $15.7 \mathrm{kcal} / \mathrm{mol}$ for the corresponding Ru model. Starting from the resting state $\mathbf{Q}$, the lowest barrier leading to the TH process turns out to be that of cycle D for the Ir systems. 


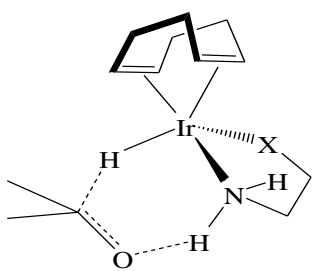

TS (cycle A)

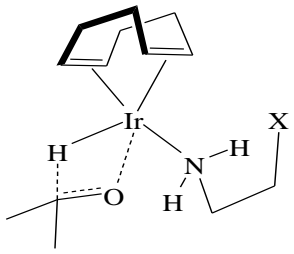

TS (cycle B)

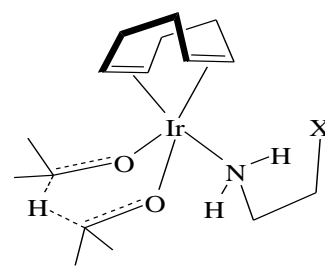

TS (cycle D)

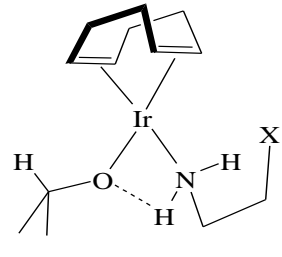

$\mathbf{Q}$

\section{Scheme 69}

Calculations on catalytic cycles that involve $\mathrm{Ir}^{\mathrm{III}}$ catalysts or intermediates have apparently not yet been reported. No calculations seem to be reported also for Ir-based hydrogenation mechanisms, which as stated above differ from $\mathrm{TH}$ only in the regeneration of the hydride complex (Scheme 58). As already mentioned, complexes containing COD or other olefins are likely to be transformed into solvent-stabilized species of type $\left[\operatorname{Ir}\left(\mathrm{LL}^{\prime}\right)\left(\mathrm{S}_{2}\right)_{2}\right]^{+}$under these conditions, although whether these are stable as $\operatorname{Ir}^{\mathrm{I}}$ derivatives or are transformed into $\mathrm{Ir}^{\mathrm{III}}$ species is not yet clear. One intriguing possibility (valid also for the TH process with $\left[\operatorname{IrCl}\left(\mathrm{LL}^{\prime}\right)\right]_{2}$ catalysts such as $\mathbf{9 6 , 9 7}$ or 99) that has apparently not yet been considered is that an outer sphere mechanism is operational, even when L and L' do not contain mobile protons, with intervention of a coordinated alcohol molecule, as shown in Scheme 70. After all, if this mechanism is proposed for alcohol functions that are part of a chelating ligand (e.g. aminoalcohols), why not for simple alcohol molecules? An ongoing computational study in our laboratory seems to confirm that this is a viable pathway [102].

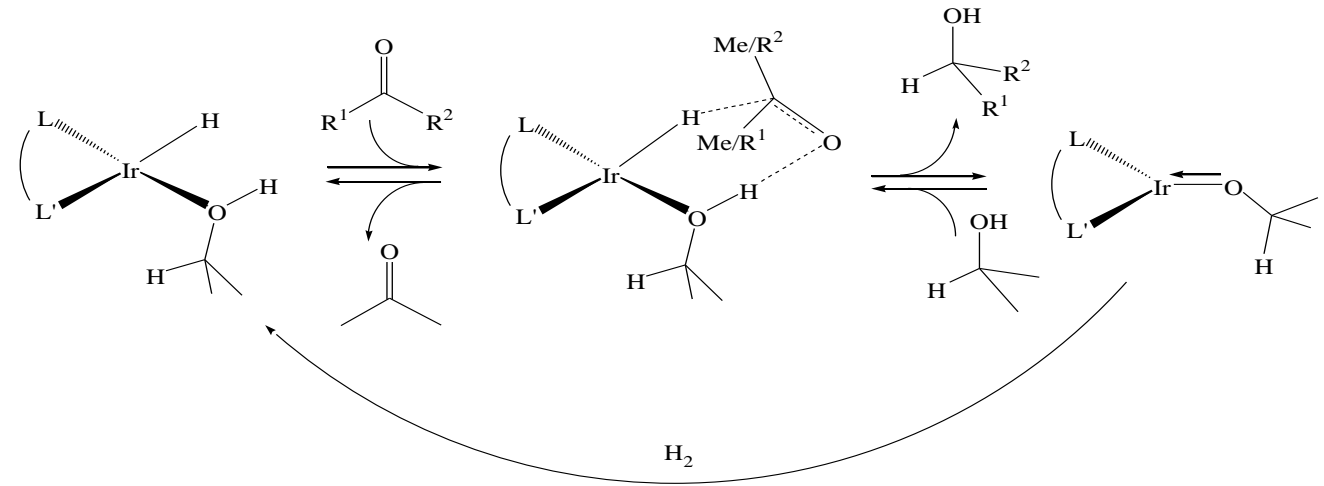

Scheme 70

\section{Conclusions}


Several iridium-based catalytic systems for asymmetric transfer hydrogenation or asymmetric hydrogenation of prochiral ketones systems have now already reached high levels of efficiency in term of activity and enantioselectivity, although there is still large room for improvement. However, iridium complexes can now be considered by synthetic chemists as useful tools to access chiral enantiomerically enriched alcohols which can complement methodologies based on $\mathrm{Ru}$ or $\mathrm{Rh}$ complexes, with respect to which it presents specific advantages, and interest in this metal will probably continue to grow.

From the point of view of the mechanistic pathways, iridium catalysis has been much less investigated than $\mathrm{Ru}$ and even $\mathrm{Rh}$ systems. The limited information obtained so far seems to indicate than a metal-templated direct transfer pathway may be operational in transfer hydrogenation for certain $\left[\operatorname{Ir}(\text { diene })\left(L^{\prime}\right)\right]^{+}$systems which retain the diene or olefins in the coordination sphere, whereas results obtained in the presence of $\mathrm{CH}_{3} \mathrm{OD}$ indicate the active participation of iridium-bonded $\mathrm{NH}$ functions in $\mathrm{H} / \mathrm{D}$ exchange processes with $\mathrm{D}$ incorporation into the $\alpha-\mathrm{C}$ position in hydrogenation processes. However, the multitude of available lowenergy pathways and the variety of coordination environments that have been found compatible with catalytic activity require many additional mechanistic investigations before reaching a full understanding of how the mechanistic pathway, activity and enantioselectivity are affected by the catalyst structure.

\section{References}

$\mathbf{1}$ (a) Chirality in Industry: The commercial Manufacture and Applications of Optically Active Compounds; A. N. Collins, G. N. Sheldrake, J. Crosby, Eds, John Wiley \& Sons : Chichester, (1992). (b) Large Scale Asymmetric Catalysis, H.U. Blaser, E. Schmidt (Eds.), Wiley-VCH: Weinheim (2003). (c) Handbook of Homogeneous Hydrogenation, J.G. de Vries and C.J. Elsevier (eds.), Wiley-VCH: Weinheim (2007), p. 1279.

2 J. C. Moore, D. J. Pollard, B. Kosjek, P. N. Devine, Acc. Chem. Res. 40 (2007) 1412.

3 (a) P. I. Dalko, L. Moisan, Angew. Chem. Int. Ed. 40 (2001) 3726; (b) B. Cambou, A. M. Klibanov, Biotechnol. Bioeng. 26 (1984) 1449; (c) A. M. Klibanov, Acc. Chem. Res. 23 (1990) 114; (d) G. M. Whitesides, C.-H. Wong, Angew. Chem. Int. Ed. 24 (1985) 617; (e) E. T. Farinas, T. Bulter, F. H. Arnold, Curr. Opin. Biotechnol. 12 (2001) 545; (f) E. T. Farinas, U. Schwaneberg,. A. Glieder, F. H. Arnold, Adv. Synth. Catal. 343 (2001) 601; (g) F. H. Arnold, Nature 409 (2001) 253; (h) J. M. Keith, J. F. Larrow, E. N. Jacobsen, Adv. Synth. Catal. 343 (2001) 5 . 
4 (a) L. A. Saudan, Acc. Chem. Res. 40 (2007) 1309; (b) T. Aida, M. Harada, T. Yamamoto, H. Iwai, A. Amano, T. Yamasaki, U. S. Patent 6,084,138, (1998) ; (c) C. Chapius, A. Gautier, P.B. Blanc, European Patent EP0643958, (1994).

5 Y. Jiang, Q. Jiang, X. Zhang, J. Am. Chem. Soc. 120 (1998) 3817.

6 (a) K. Matsumura, S. Hashinguchi, T. Ikariya, R. Noyori, J. Am. Chem. Soc. 119 (1997) 8738; (b) A. Fujii, S. Hashiguchi, N. Uematsu, T. Ikariya, R. Noyori, J. Am. Chem. Soc. 118 (1996) 2521; (c) S. Hashiguchi, A. Fujii, J. Takehara, T. Ikariya, R. Noyori, J. Am. Chem. Soc. 117 (1995) 7562.

7 (a) K. Murata, T. Ikariya, J. Org. Chem. 64 (1999) 2186; (b) J. Mao, D. C. Baker, Org. Lett. 1 (1999) 841.

${ }^{8}$ S. J. Roseblade, A. Pfaltz, Acc. Chem. Res. 40 (2007) 1402.

9 Values based on www.platinum.matthey.com.

${ }^{10}$ A more general review on iridium-catalyzed hydrogenation and transfer hydrogenation, including asymmetric versions, has appeared recently as a monograph chapter: Bianchini, C., Gonsalvi, L., Peruzzini, M. 55-106, in Iridium complexes in Organic Synthesis , L. Oro, C. Claver, Eds, Wiley-VCH: Weinheim, (2009).

11 (a) E. N. Jacobsen, A. Pfalz, H. Yamamoto, Comprehensive Asymmetric Catalysis; Springer: Berlin, (1999), Vols.1-3; (b) I. Ojima, Catalytic Asymmetric Synthesis; Wiley-VCH: New York, (2000); (c) O. Riant, N. Mostefai, J. Coumarcel, Synthesis 18 (2004) 2943.

${ }^{12}$ D. C. Apple, K. A. Brady, J. M. Chance, N. E. Heard, T. A. Nile, J. Mol. Catal. 29 (1985) 55

${ }^{13}$ A. Kinting, H.-J. Kreuzfeld, H.-P. Abicht, J. Organomet. Chem. 370 (1989) 343.

14 (a) Y. Nishibayashi, K. Segawa, K. Ohe, S. Uemura, Organometallics 14 (1995) 5486; (b) Y. Nishibayashi, K. Segawa, H. Tanaka, K. Ohe, S. Uemura, Chem. Commun. (1996) 847. (c) S. Uemura, Phosphorus, Sulfur, Silicon and the Related Elements 136,137\&138 (1998) 219.

15 A. S. Frölander, C. Moberg, Org. Lett. 9 (2007) 1371.

${ }^{16}$ J. W. Faller, K.J. Chase, Organometallics 13 (1994) 989.

${ }^{17}$ Y. Nishibayashi, K. Segawa, J. D. Singh, S. Fukuzawa, K. Ohe, S. Uemura, Organometallics 15 (1996) 370.

${ }^{18}$ A. R. Chianese, R. H. Crabtree, Organometallics 24 (2005) 4432.

19 (a) G. Mestroni, G. Zassinovich, A. Camus, J. Organomet. Chem. 140 (1977) 63. (b) A. Camus, J. Mol. Catal. 6 (1979) C10. G. Mestroni, G. Zassinovich, (c) G. Mestroni, G. Zassinovich, A. Camus, F. Martinelli, J. Organomet. Chem. 198 (1980) 87. (d) F. Martinelli, G. Mestroni, G. Zassinovich, A. Camus, J. Organomet. Chem. 220 (1981) 383.

${ }^{20}$ R. Spogliarich, G. Zassinovich, J. Kaspar, M. Graziani, J. Mol. Cat. 16 (1982) 359. 
${ }^{21}$ R. Spogliarich, J. Kaspar, M. Graziani, F. Morandini, J. Organomet. Chem. 306 (1986) 407. ${ }^{22}$ H. W. Krause, A. K. Bhatnagar, J. Organomet. Chem. 302 (1986) 265.

${ }^{23}$ P. Kvintovics, J. Bakos, B. Heil, J. Mol. Cat. 32 (1985) 111.

${ }^{24}$ G. Zassinovich, G. Mestroni, S. Gladiali, Chem. Rev. 92 (1992) 1051.

${ }^{25}$ G. Zassinovich, G. Mestroni, J. Mol. Cat. 42 (1987) 81.

${ }^{26}$ G. Zassinovich, R. Bettella, G. Mestroni, N. Bresciani-Pahor, S. Geremia, L. Randaccio, J. Organomet. Chem. 370 (1989) 187.

${ }^{27}$ J. Kaschig, European Patent 0,246,194,A2, (1987).

${ }^{28}$ D. Müller, G. Umbricht, B. Weber, A. Pfaltz, Helv. Chim. Acta 74 (1991) 232.

${ }^{29}$ N. Debono, M. Besson, C. Pinel, L. Djakovitch, Tetrahedron Letters 45 (2004) 2235.

${ }^{30}$ P. Gamez, B. Dunjic, M. Lemaire, J. Org. Chem. 61 (1996) 5196.

${ }^{31}$ Y. Nishibayashi, J. D. Singh, Y. Arikawa, S. Uemura, M. Hidai, J. Organomet. Chem. 531 (1997) 13.

32 S.-I. Inoue, K. Nomura, S. Hashiguchi, R. Noyori, Y. Izawa, Chem. Lett. 9 (1997) 957.

${ }^{33}$ R. ter Halle, A. Bréhéret, E. Schulz, C. Pinel, M. Lemaire, Tetrahedron: Asymmetry 8 (1997) 2101.

${ }^{34}$ V. A. Pavlov, M. G. Vinogradov, E. V. Starodubetsva, G. V. Chel'tsova, V. A. Ferapontov, O. R. Malyshev, G. L. Heise, Russ. Chem. Bull. Int. Ed. 50 (2001) 734.

${ }^{35}$ A. Hartikka, S. A. Modin, P. G. Andersson, P. I. Arvidsson, Org. Biomol. Chem. 1 (2003) 2522.

${ }^{36}$ J. A. Fuentes, M. B. France, A.M. Z. Slawin, M. L. Clarke, New J. Chem. 33 (2009) 466.

${ }^{37}$ A. Trifonova, K. A. Källström, P. G. Andersson, Tetrahedron 60 (2004) 3393.

${ }^{38}$ S. Hashiguchi, A. Fujii, J. Takehara, T. Ikariya, R. Noyori, J. Am. Chem. Soc. 117 (1995) 7562.

${ }^{39}$ K. Mashima, T. Abe, K. Tani, Chem. Lett. 12 (1998) 1199.

${ }^{40}$ K. Murata, T. Ikariya, R. Noyori, J. Org. Chem. 64 (1999) 2186.

41 T. Thorpe, J. Blacker, S. M. Brown, C. Bubert, J. Crosby, S. Fitzjohn, J. P. Muxworthy, J. M. Williams, Tetrahedron Lett. 42 (2001) 4041.

42 X. Wu, D. Vinci, T. Ikariya, J. Xiao, Chem. Commun. 35 (2005) 4447.

${ }^{43}$ X. Wu, X. Li, A. Zanotti-Gerosa, A. Pettman, J. Liu, A. J. Mills, J. Xiao, Chem. Eur. J. 14 (2008) 2209.

${ }^{44}$ X. Li, J. Blacker, I. Houson, X. Wu, J. Xiao, Synlett 8 (2006) 1155.

${ }^{45}$ D. Carmona, F. J. Lahoz, R. Atencio, L. A. Oro, M. P. Lamata, F.Viguri, E. San José, C. Vega, J. Reyes, F. Joo, A. Katho, Chem. Eur. J. 5 (1999) 1544. 
${ }^{46}$ W. He, B.-L. Zhang, R. Jiang, P. Liu, X.-L. Sun, S.-Y. Zhang, Tet. Lett. 47 (2006) 5367.

${ }^{47}$ W. He, P. Liu, B.-L. Zhang, X.-L. Sun, S.-Y. Zhang, Appl. Organometal. Chem. 20 (2006) 328.

${ }^{48}$ X. Wu, X. Li, M. McConville, O. Saidi, J. Xiao, J. Mol. Cat. A: Chemical 247 (2006) 153.

${ }^{49}$ K. Aboulaala, C. Goux-Henry, D. Sinou, M. Safi, M. Soufiaoui, J. Mol. Cat. A: Chemical 227 (2005) 259.

${ }^{50}$ D. G. I. Petra, P. C. J. Kamer, A. L. Spek, H. E. Schoemaker, P. W. N. M. Van Leeuwen, J. Org. Chem. 65 (2000) 3010.

${ }^{51}$ A. Hage, D. G. I. Petra, J. A. Field, D. Schipper, J. B. P. A. Wijnberg, P. C. J. Kamer, J. N. H. Reek, P. W. N. M. van Leeuwen, R. Wever, H. E. Schoemaker, Tetrahedron: Asymmetry $12(2001) 1025$.

52 A. Gayet, C. Bolea, P. G. Andersson, Org. Biomol. Chem. 2 (2004) 1887.

${ }^{53}$ H. Seo, B. Y. Kim, J. H. Lee, H.-J. Park, S. U. Son, Y. K. Chung, Organometallics 22 (2003) 4783.

${ }^{54}$ P. Maire, F. Breher, H. Schönberg, H. Grützmacher, Organometallics 24 (2005) 3207.

55 Y.-Y. Li, H. Zhang, J.-S. Chen, X.-L. Liao, Z.-R. Dong, J.-X. Gao, J. Mol. Cat. A: Chemical 218 (2004) 153.

56 J.-S. Chen, Y.-Y. Li, Z.-R. Dong, B.-Z. Li, J.-X. Gao, Tet. Lett. 45 (2004) 8415.

57 Y. Xing, J.-S. Chen, Z.-R. Dong, Y.-Y. Li, J.-X. Gao, Tet. Lett. 47 (2006) 4501.

58 Z.-R. Dong, Y.-Y. Li, J.-S. Chen, B.-Z. Li, Y. Xing, J.-X. Gao, Org. Lett. 7 (2005) 1043.

${ }^{59}$ B.-Z. Li, J.-S. Chen, Z.-R. Dong, Y.-Y. Li, Q.-B. Li, J.-X. Gao, J. Mol. Cat. A: Chemical 258 (2006) 113.

${ }^{60}$ W.-Y. Shen, H. Zhang, H.-L. Zhang, J.-X. Gao, Tetrahedron: Asymmetry 18 (2007) 729.

${ }^{61}$ X.-Q. Zhang, Y.-Y. Li, H. Zhang, J.-X. Gao, Tetrahedron: Asymmetry 18 (2007) 2049.

${ }^{62}$ G. Chen, Y. Xing, H. Zhang, J.-X. Gao, J. Mol. Cat. A: Chemical 273 (2007) 284.

${ }^{63}$ P. Paredes, J. Diez, M. P. Gamasa, Organometallics 27 (2008) 2597.

${ }^{64}$ Y.-M. Zhang, P. Liu, H.-L. Zhang, Z.-M. Zhou, Synthesis and Reactivity in Inorganic, MetalOrganic, and Nano-Metal Chemistry, 387 (2008) 577.

${ }^{65}$ R. J. Ludgren, M. Stradiotto, Chem. Eur. J. (2008) 10388.

${ }^{66}$ J. Solodar, Monsanto Co. Chemical Technology 5 (1975) 421.

${ }^{67}$ E. Cesarotti, L. Prati, M. Pallavicini, L. Villa, R. Spogliarich, E. Farnetti, M. Graziani, J. Mol. Cat. 62 (1990) L29.

${ }^{68}$ X. Zhang, T. Taketomi, T. Yoshizumi, H. Kumobayashi, S. Akutagawa, K. Mashima, H. Takaya, H.; J. Am. Chem. Soc. 115 (1993) 3318. 
${ }^{69}$ X. Zhang, H. Kumobayashi, H. Takaya, Tetrahedron Asymm. 5 (1994) 1179.

${ }^{70}$ S. Agutagawa, H. Kumobayashi, K. Mashima, H. Takaya, European Patent 0,479,541,A1, (1991).

71 (a) K. Makino, Y. Hiroki, Y. Hamada, J. Am. Chem. Soc. 127 (2005) 5785. (b) K. Makino, M. Iwasaki, Y. Hamada, Org. Lett. 8 (2006) 4573.

${ }^{72}$ C. Pinel, N. Geandreau-Diaz, A. Bréhéret, M. Lemaire, J. Mol. Cat. A: Chemical 112 (1996) L157.

${ }^{73}$ M. L. Tommasino, C. Thomazeau, F. Touchard, M. Lemaire, Tet. Asymm. 10 (1999) 1813.

${ }^{74}$ A. Ferrand, M. Bruno, M. L. Tommasino, M. Lemaire, Tet. Asymm. 13 (2002) 1379.

75 C. Maillet, T. Praveen, P. Janvier, S. Minguet, M. Evain, C. Saluzzo, M. L. Tommasino, B. Bujoli, J. Org. Chem. 67 (2002) 8191.

${ }^{76}$ T. Ohkuma, N. Utsumi, M. Watanabe, K. Tsutsumi, N. Arai, K. Murata, Org. Lett. 9 (2007) 2565 .

${ }^{77}$ G. Liu, M. Yao, J. Wang, X. Lu, M. Liu, F. Zhang, H. Li, Angew. Chem. Int. Ed. 47 (2008) 1464.

78 (a) T. Marzialetti, J. L. G. Fierro, P. Reyes, Catal. Today 107-108 (2005) 235. (b) T.

Marzialetti, M. Oportus, D. Ruiz, J. L. G. Fierro, P. Reyes, Catal. Today 133-135 (2008) 711.

${ }^{79}$ H.-Y. Jiang, C.-F. Yang, C. Li, H.-Y. Fu, H. Chen, R.-X. Li, X.-J. Li, Angew. Chem. Int. Ed. 47 (2008) 9240.

${ }^{80}$ C.-F. Yang, H.-Y. Jiang, J. Feng, H.-Y. Fu, R.-X. Li, H. Chen, X.-J. Li, J. Mol. Cat. A: Chemical 300 (2009) 98.

${ }^{81}$ E. D. Martins, D. J. Morris, M. Wills, Tet. Lett. 50 (2009) 688.

${ }^{82}$ L. Dahlenburg, R. Götz, Eur. J. Inorg. Chem. (2004) 888.

${ }^{83}$ L. Dahlenburg, R. Menzel, F. W. Heinemann, Eur. J. Inorg. Chem. (2007) 4364.

${ }^{\mathbf{8 4}}$ E. Le Roux, R. Malacea, E. Manoury, R. Poli, L. Gonsalvi, M. Peruzzini, Adv. Synth. Catal. 349 (2007) 309.

${ }^{85}$ K. Abdur-Rashid, S. E. Clapham, A. Hadzovic, J. N. Harvey, A. J. Lough, R. H. Morris, J. Am. Chem. Soc. 124 (2002) 15104.

${ }^{86}$ J. S. M. Samec, J. E. Backvall, P. G. Andersson, P. Brandt, Chem. Soc. Rev. 35 (2006) 237.

${ }^{87}$ O. Pamies, J. E. Backvall, Chem. Eur. J. 7 (2001) 5052.

${ }^{88}$ M. Albrecht, J. R. Miecznikowski, A. Samuel, J. W. Faller, R. H. Crabtree, Organometallics 21 (2002) 3596.

${ }^{89}$ As pointed out by a reviewer, in case the hydride complex can be obtained as a mixture of diastereoisomers and if a chiral and enantiopure hydrogen donor can transfer the $\mathrm{H}$ atom to the 
metal diastereoselectively, then the chirality of the H-donor might indirectly exert its influence on the reaction stereoselectivity. We note, however, that most ATH reactions are carried out with achiral $\mathrm{H}$ donor molecules (isopropanol, formic acid).

${ }^{90}$ R. Noyori, Angew. Chem., Int. Ed. Eng. 41 (2002) 2008.

${ }^{91}$ W. Baratta, G. Chelucci, S. Gladiali, K. Siega, M. Toniutti, M. Zanette, E. Zangrando, P. Rigo, Angew. Chem., Int. Ed. Engl. 44 (2005) 6214.

${ }^{92}$ Z. E. Clarke, , P. T. Maragh, T. P.Dasgupta, D. G. Gusev, A. J. Lough, K. Abdur-Rashid, Organometallics 25 (2006) 4113.

${ }^{93}$ R. H. Crabtree, P. C. Demou, D. Eden, J. M. Mihelcic, C. A. Parnell, J. M. Quirk, G. E. Morris, J. Am. Chem. Soc. 104 (1982) 6994.

${ }^{94}$ E. Farnetti, J. Kaspar, R. Spogliarich, M. Graziani, J. Chem. Soc., Dalton Trans. (1988) 947.

${ }^{95}$ L. Dahlenburg, R. Götz, Inorg. Chim. Acta 357 (2004) 2875.

96 (a) H. J. Drexler, W. Baumann, A. Spannenberg, C. Fischer and D. Heller, J. Organomet. Chem. 621 (2001) 89. (b) D. Heller, H. J. Drexler, J. S. You, W. Baumann, K. Drauz, H. P. Krimmer, A. Börner, Chem. Eur. J. 8 (2002) 5196.

${ }^{97}$ R. H. Crabtree, H. Felkin, and G. E. Morris, J. Organomet. Chem. 141 (1997) 205.

${ }^{98}$ M. Bernard, V. Guiral, F. Delbecq, F. Fache, P. Sautet, M. Lemaire, J. Am. Chem. Soc. 120 (1998) 1441.

${ }^{99}$ V. Guiral, F. Delbecq, P. Sautet, Organometallics 19 (2000) 1589.

100 (a) V. Guiral, F. Delbecq, P. Sautet, Organometallics 20 (2001) 2207. (b) F. Delbecq, V. Guiral, P. Sautet, Eur. J. Org. Chem. (2003) 2092.

${ }^{101}$ J. W. Handgraaf, J. N. H. Reek, E. J. Meijer, Organometallics 22 (2003) 3150.

102 J. M. Hayes, G. Ujaque, A. Lledós, R. Malacea, E. Manoury, S. Vincendeau, R. Poli, in preparation. 